\title{
Risk analysis in Natech events: State of the art
}

\author{
Adriana María Mesa Gómez ${ }^{\mathrm{a}, \mathrm{b}, 1}$, Joaquim Casal Fabrega ${ }^{\mathrm{b}}$, Felipe Muñoz Giraldo ${ }^{\mathrm{a}}$ \\ ${ }^{a}$ Chemical Engineering Department, Universidad de los Andes, Bogotá, Colombia \\ ${ }^{\mathrm{b}}$ Centre for Technological Risk Studies, Universitat Politècnica de Catalunya, Barcelona, Catalonia, \\ Spain
}

\begin{abstract}
Natech events (Natural Hazard Triggering Technological Disasters) are industrial accidents caused by natural events such as hurricanes, floods, earthquakes, tsunamis, and so on. In recent decades, the probability of these events occurring has increased, activating the interest of researchers in the study of new methods of risk analysis to prevent and mitigate possible damage to people, the environment, and processing facilities. On the other hand, the concept of multi-hazard is summarized in the combination of two or more threat factors manifested in isolated, simultaneous manner, or by chain reaction, to produce a trigger event of a disaster, where hazardous events can be one or more natural events. Considering that, it is essential to know the progress in risk analysis for Natech events, to identify the gaps for future research. Therefore, in this paper, a systematic review of the Natech events literature with single and multi-hazard approaches was developed. The review was conducted by searching the Science Direct, Web of Science, and Scopus databases for scientific documents. Subsequently, the words Natech and Multi-hazard were taken as keywords, and 208 results were obtained. Then, some management documents were consulted in international organizations to compare academic literature and industrial risk management. In conclusion, the risk analysis methods revised are specific to a particular hazard and apply mainly to earthquakes, floods, and lightning. Regarding a multi-hazard approach, the methods focus on risk mitigation in urban areas without taking into account Natech risk. In the case of industrial risk assessment, some methodologies were found that briefly consider Natech risk in risk assessment processes in industry.
\end{abstract}

Keywords: Natech, Risk, Disaster, Natural event, Multi-hazard.

\footnotetext{
${ }^{1}$ Corresponding author.

E-mail address: am.mesa@uniandes.edu.co

Full postal address: Cra 1 N$^{\circ}$ 19A- 40, edificio Mario Laserna, piso 7, Bogotá, (Colombia)
} 


\section{Contents}

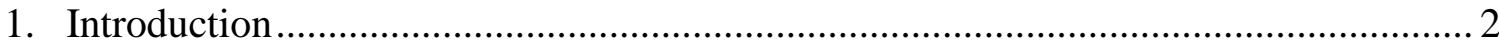

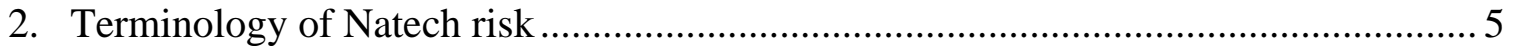

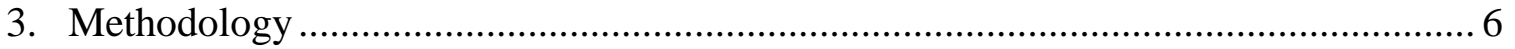

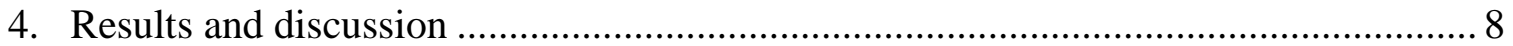

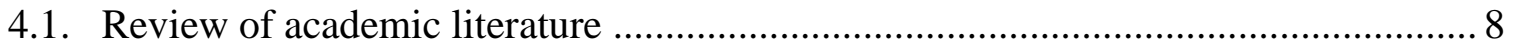

4.1.1. Analysis of publications based on single hazard analysis ................................... 8

4.1.2. Analysis of publications based on multi-hazard analysis .................................. 21

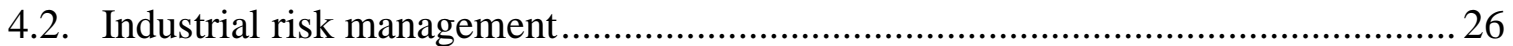

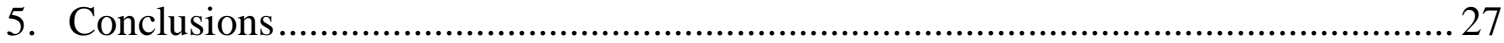

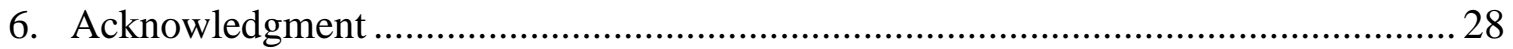

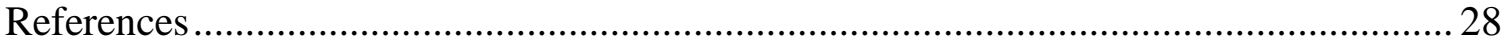

\section{Introduction}

Natural hazards (e.g., hurricanes, strong winds, lightning, floods, landslides, and so on) represent significant threats to process units of different industries, either offshore or onshore. These natural hazards can affect industrial facilities producing loss of containment (LOC) in process equipment that store hazardous materials causing fires, explosions, or toxic cloud emissions (Casal, 2018) and generating significant impact on the environment and the surrounding population. Thus, a technological accident involving the release of hazardous materials caused by a natural hazard is well known as Natech: Natural Hazard Triggering Technological Disasters (Cruz \& Krausmann, 2013).

Natech events have produced significant impacts in different parts of the world and have become an issue of great relevance to modern society. For instance, the two hurricanes Katrina and Rita in 2005, in the Gulf of Mexico (United States) resulted in multiple damages to approximately 611 industrial equipment such as offshore platforms, oil pipelines, and storage tanks (Krausmann \& Cruz, 2017) or the great East Japan earthquake and tsunami on the chemical industry with consequences for people and the environment (Krausmann \& Cruz, 2013). Although up to now it has been thought that these events have a low probability of occurrence, they have a significant impact and a high level of complexity regarding risk management because they are the result of cascading events (Nascimento \& Alencar, 2016). However, the frequency of occurrence of this type of events has varied over time, taking in consideration that the probability of occurrence is higher concerning the past decades (see Figure 1). In addition, the high-impact and low-probability (HILP) scenarios, such as technological events triggered by natural hazards in industrial sites, are generating a significant concern; however, the analysis of HILP events is a relatively new challenge faced by people involved in disaster risk management and can be particularly complicated. Its complexity highlights the importance of studying and analyzing past events, emphasizing that the lessons learned from historical accidents investigations should be adopted while preparing for possible future incidents. All in all, accident investigation methods help to 
understand better the course of events and causes that produce them (Chakraborty, Ibrahim, \& Cruz, 2018).

On the other hand, the concept of multi-hazard is summarized in the combination of two or more threat factors manifested in isolated, simultaneous manner or by chain reaction, to produce a trigger event of a disaster, where threat factors can be natural events (definition taken from the National Commission for Risk Prevention and Emergency Care, Costa Rica). In the above context, the number of people affected by natural hazards is currently increasing (Arnold et al., 2006). This is because many regions of the world are subjected to multiple natural hazards, and although the scientific knowledge on the risk subject is also increasing, the losses from natural catastrophes due to the late transfer from theory to practice (Komendantova et al., 2014). As the scientific evidence shows, decision-makers face the challenge of mitigating not only the single risks and hazards, but also their interrelations. As the concept of multi-hazard is a relatively young area of natural hazard governance, there are few multi-hazard models to assess the individual and social risk in populated areas due to natural events, but the experience of the professionals in how to use these models is limited (Komendantova et al., 2014).

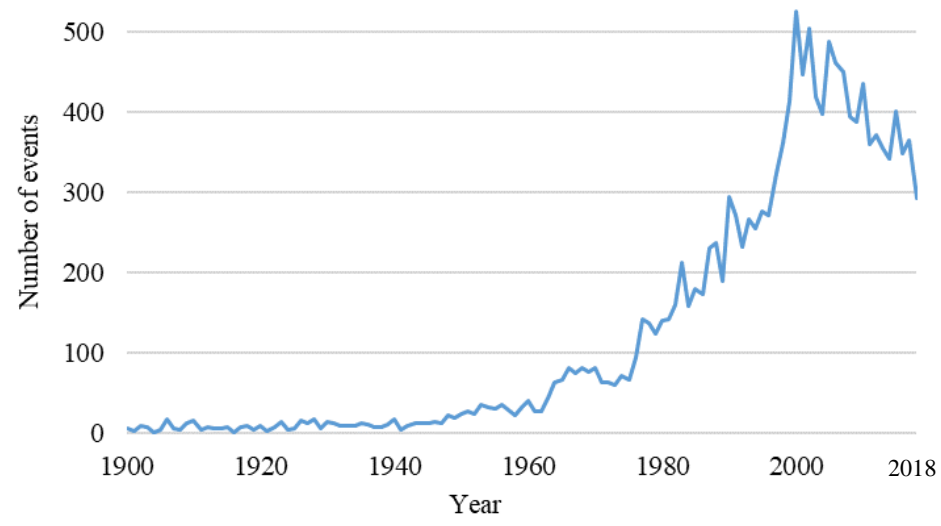

Figure 1. Number of reported disaster events. Source: (EMDAT, 2019)

For these reasons, in recent years, the scientific community has devoted more attention to Natech risk assessment and multi-hazard risk assessment; for instance, many risk analysis with multi-hazard approaches were proposed in Europe and around the world to adequately address this challenge, with the aim of creating tools and procedures for integrated risk analysis. For instance, some authors stressed the crucial role of dedicated land use practices, such as (Cruz, Steinberg, \& Vetere-Arellano, 2006) who proposed that the common land-use practices could be an extremely effective method to reduce the risk of Natech events. In brief, this kind of work has generated the need to design new risk analysis methodologies to mitigate the possible damage that may materialize.

The purpose of this review is to know the development about Natech risk analyses in order to identify gaps in this kinds of analysis, and in the same way, to compare what the academic literature propose in contrast with what the international agencies are applying in process units. Some works considering a single hazard were found, which present methods to assess Natech risk considering specific natural events. For instance, (Cruz \& Okada, 2008) proposed a method for preliminary assessment of Natech risk in urban areas to mitigate 
emissions of hazardous materials from nearby industrial facilities, or facilities which store chemicals or equipment that contain hazardous materials in urban areas; however, subsequent to this work, more robust methodologies which include qualitative analyses have been developed. These include: framework for the assessment of Natech (Krausmann, Cozzani, Salzano, \& Renni, 2011), methodology Bow-tie to perform risk analysis in flood-prone facilities (C. El Hajj, Piatyszek, \& Laforest, 2012), fragility curves for pipelines that include land use planning (Lanzano, Salzano, de Magistris, \& Fabbrocino, 2013), systematic methodology for analysis of flood risks (Carine El Hajj, Piatyszek, Tardy, \& Laforest, 2015); semi-quantitative analyses such as: computational tool RAPID-N (Girgin \& Krausmann, 2013), methodology to carry out risk assessments through the analysis of cascade effects (Kadri, Birregah, \& Chatelet, 2014), geographic information system-based methodology (Soto \& Renard, 2015). In terms of quantitative analyses, (Ernesto Salzano, Garcia Agreda, Di Carluccio, \& Fabbrocino, 2009), developed comprehensive quantitative risk assessment (QRA) methodologies, inserting domino effect risk and the risk associated with nature in the QRA. The authors focused on events, such as floods, earthquakes, and lightning, developing new tools to identify the most frequent modes of damage and occurrence scenarios associated with them. However, other relevant approaches have been proposed such as: methodology for quantitative estimation of the influence of external events at the industrial risk (Campedel, Cozzani, Garcia-Agreda, \& Salzano, 2008), a procedure for the quantitative evaluation of industrial risk due to LOC of hazardous substances by lightning impact (Renni, Krausmann, \& Cozzani, 2010), a general methodology to assess the risk of loss of life introduced by the hazardous chemical dispersion transported by air after seismically-induced chemical release (Meng, Lu, Yan, Shi, \& Liu, 2015), models of physical reliability-based methodology and Bayesian networks to evaluate the fragility of industrial plants to floods (Khakzad \& Van Gelder, 2018).

However, some works considering a multi-hazard were found, which present methods to assess natural risk considering interactions between some natural events, but without a Natech approach. (Gallina et al., 2016) conducted a literature review where the authors found that most of the methodologies analyzed to deal with the assessment of natural hazards in urban areas did not take into account Natech risk. Additionally, for multi-hazard assessment, most methods consider hazards as independent events. Potential interactions are analyzed through a cause-effect matrix that allows a semi-quantitative estimation of the relationships between agents and processes in the evolution of a system.

Taking into account the above, this document presents a chronological review of the literature pertaining risk analysis of Natech events with a single hazard approach and a multihazard approach. It is important to highlight that analyses with single hazard approach have the majority of the results in contrast with analyses with multi-hazard approach. In fact, the main finding is that the approach of the proposed risk analysis and methods is specific to one hazard in particular, and the most discussed are earthquakes, floods, and lightning. For this reason, most of the institutions and industries have designed and implemented contingency plans focused on a specific hazard. Nevertheless, the office of the United Nations Office for Disaster Risk Reduction (UNISDR) declared that to cope with the trend of increasing in intensity and frequency of disasters in recent years, the Sendai framework for disaster risk reduction 2015-2030 calls to strengthen the methods for reducing the risk of disasters by using assessments, maps, monitoring and early warning multi-hazard systems, and the creation of multi-hazard comprehensive studies. 


\section{Terminology of Natech risk}

A list of the terminology used in this document and the corresponding definitions is presented in this section.

Cascading event: chain of events in which a primary event triggers a secondary event, which in turn can cause a tertiary event, and so on. During Natech events, the risk of cascading events is generally higher than during conventional technological accidents (Krausmann, Cruz, \& Salzano, 2017).

Consequence: outcome of an event which can be positive or negative. An event can have more than one outcome (Krausmann, Cruz, et al., 2017).

Disaster: natural or man-made event resulting in widespread human, environmental, economic, or material losses. The adverse consequences of a disaster can exceed the ability of the affected community or society to cope using its own resources (Krausmann, Cruz, et al., 2017).

Dynamic vulnerability: change in vulnerability due to the cascading sequence of events (Zuccaro \& Leone, 2018).

Fragility curve: probability of failure or damage as a function of the degree of natural event loading experienced (Krausmann, Cruz, et al., 2017).

Frequency (relative): likelihood of an event over a specific time interval, usually expressed as year ${ }^{-1}$ (Krausmann, Cruz, et al., 2017).

Hazard: source of danger. A hazard does not necessarily lead to harm but represents only a potential to result in harm (Krausmann, Cruz, et al., 2017).

Hazardous material: biological, chemical, radiological, or nuclear agent which poses a threat to health, animals, or the environment (Krausmann, Cruz, et al., 2017).

Multi-hazard: (1) the selection of multiple major hazards that the country faces, and (2) the specific contexts where hazardous events may occur simultaneously, as a cascade, or cumulatively over time, and taking into account the potential interrelated effects.

Natech: technological accident involving the release of hazardous materials caused by a natural hazard. The releases can be chemical, biological, or radiological in nature (Krausmann, Cruz, et al., 2017).

Natech event: technological accidents caused by natural events such as hurricanes, floods, earthquakes, tsunamis, and so on. The consequences can be: explosions, dispersion of hazardous materials, or fires. 
Probability: measure for the likelihood of a random event expressed as a number between 0 and 1 (Krausmann, Cruz, et al., 2017).

QRA: Quantitative Risk Analysis or Assessment. Process to estimate the risk of an event quantitatively. The outcome of a QRA is usually expressed in terms of facilities or economic losses (Krausmann, Cruz, et al., 2017).

Risk: combination of the frequency, or probability, of occurrence and the consequences of a hazardous event. Risk therefore includes the likelihood of conversion of a hazard into actual delivery of injury, damage, or harm. Risk is always subject to uncertainty related to the occurrence of the event (Krausmann, Cruz, et al., 2017).

Risk analysis: process that identifies hazard sources and estimates the associated risk (Krausmann, Cruz, et al., 2017).

Risk assessment: risk analysis and risk evaluation (Krausmann, Cruz, et al., 2017).

Risk evaluation: process by which the estimated risk is compared to given risk acceptability criteria (Krausmann, Cruz, et al., 2017).

Risk management: process that includes risk assessment, risk treatment, risk acceptance, and risk communication (Krausmann, Cruz, et al., 2017).

Risk treatment: selection and implementation of measures to modify the estimated risk (Krausmann, Cruz, et al., 2017).

Vulnerability: the conditions determined by physical, social, economic and environmental factors or processes which increase the susceptibility of an individual, a community, assets or, systems to the impacts of hazards (Zuccaro \& Leone, 2018).

\section{Methodology}

To obtain an overview of the existing Natech methodologies, a review was carried out both in academic literature and in management documents used in the industry and developed by international organizations.

To find the evolution and the current status of the research for Natech events, the flowchart of the documents classification process for academic literature presented in Figure 2 was developed. In the case of industrial management, international organizations such as API, CCPS, EPA, FEMA, Seveso Directive, and OCDE were consulted. 


\section{Criteria}

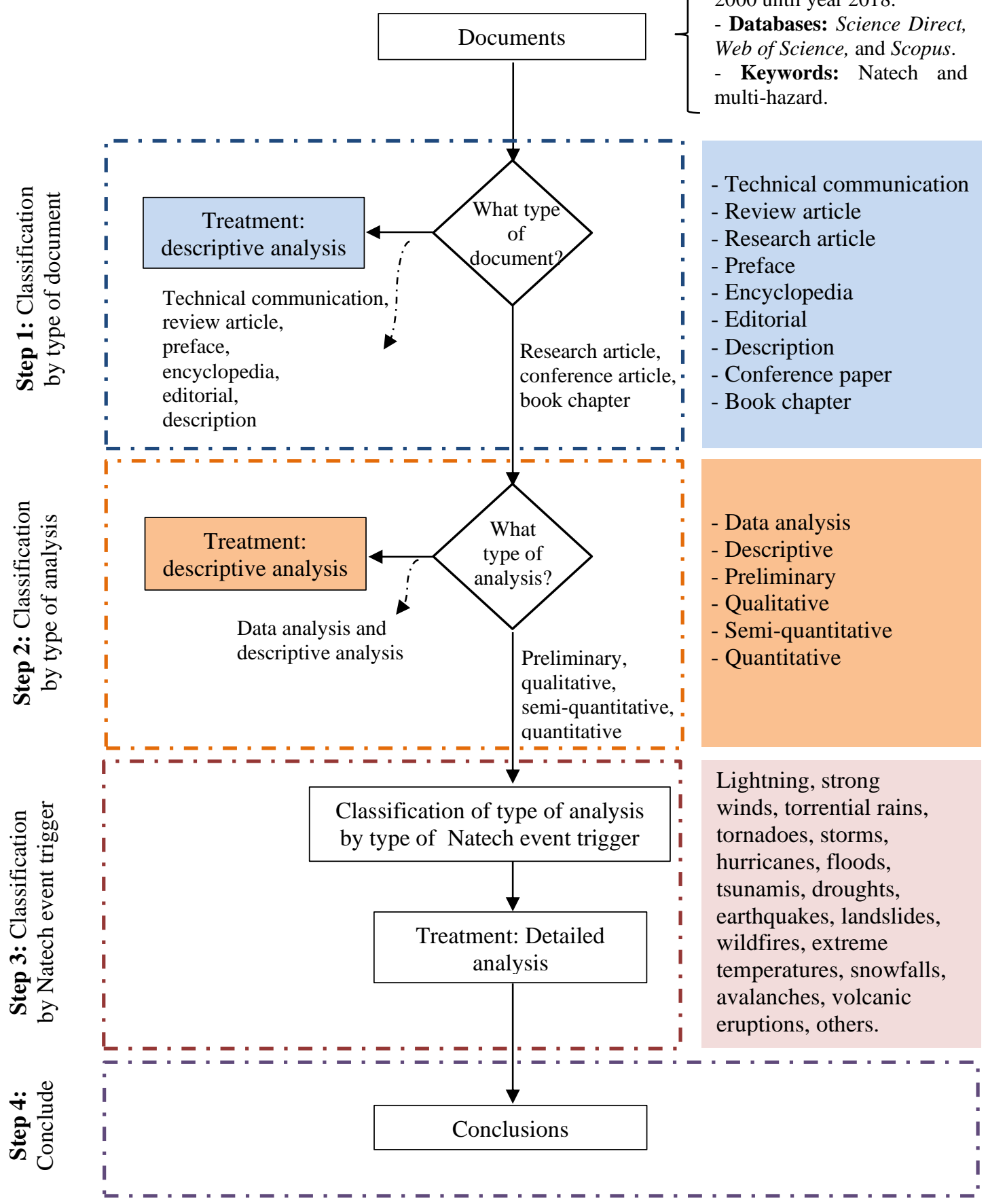

Figure 2. Flowchart of the documents classification process for academic literature.

Criteria used to define each academic document for analysis were technical communications, review articles, research articles, prefaces, encyclopedias, journal editorials, descriptions, conference papers, and book chapters. 
Criteria used to define each type of analysis were:

- Descriptive analysis: case studies, analysis of historical events, description of phenomena, book chapters (with descriptive content), descriptions, technical communications, journal editorials, encyclopedias, prefaces, technical communications, and texts with information extracted from databases without a respective statistical treatment.

- Data analysis: texts that referenced official databases as the primary source for their analysis and presented results with data processing. It also consider works that was based on data collected through field studies, surveys, and so on.

- Preliminary: texts that include preliminary data analysis or risk analysis.

- Qualitative: texts that include qualitative risk analysis, that is, with qualification based on expert judgment.

- Semi-quantitative: texts that include semi-quantitative risk or data analysis, that is, qualifications based on expert judgments and quantification of results based on proposed or existing mathematical models. This criterion covers vulnerability calculations, fragility curves, failure probabilities, and others.

- Quantitative: texts that include quantitative risk or data analysis, that is, ratings from historical data analysis and quantification of results based on proposed or existing mathematical models. This criterion covers vulnerability calculations, fragility curves, failure probabilities, and others.

Under the literature review methodology design, 189 Natech related publications focused on single hazards, 31 publications with a multi-hazard focus, and 6 publications that support the work carried out by international organizations in this type of risk were found.

\section{Results and discussion}

The results and their analysis are presented below.

\subsection{Review of academic literature}

The review of academic literature was divided into publications based on single hazards, and publications regarding multi-hazards.

\subsubsection{Analysis of publications based on single hazard analysis}

Under the proposed methodology in the Figure 2, 92\% of the works are distributed in research articles, conference papers, and book chapters (see Table 1). Most of the documents (173 documents) present a significant contribution to the Natech topic. 69\% of the research carried out is concentrated in universities and research centers located in Italy, the United States, Japan, and the United Kingdom (see Figure 3). The University of Bologna (Italy) is the institution with most contributions in the Natech topic, followed by European Commission, Joint Research Center (JRC) also located in Italy. Concerning collaborations, the University of Bologna (Italy), the JRC (Italy), and the Kyoto University (Japan) are the institutions with most publications in collaboration with other institutions. Moreover, Elizabeth Kraussman 
(JRC), Amos Necci (University of Bologna), Valerio Cozzani (University of Bologna), and Ana Maria Cruz (Kyoto University) are the authors who have the most publications.

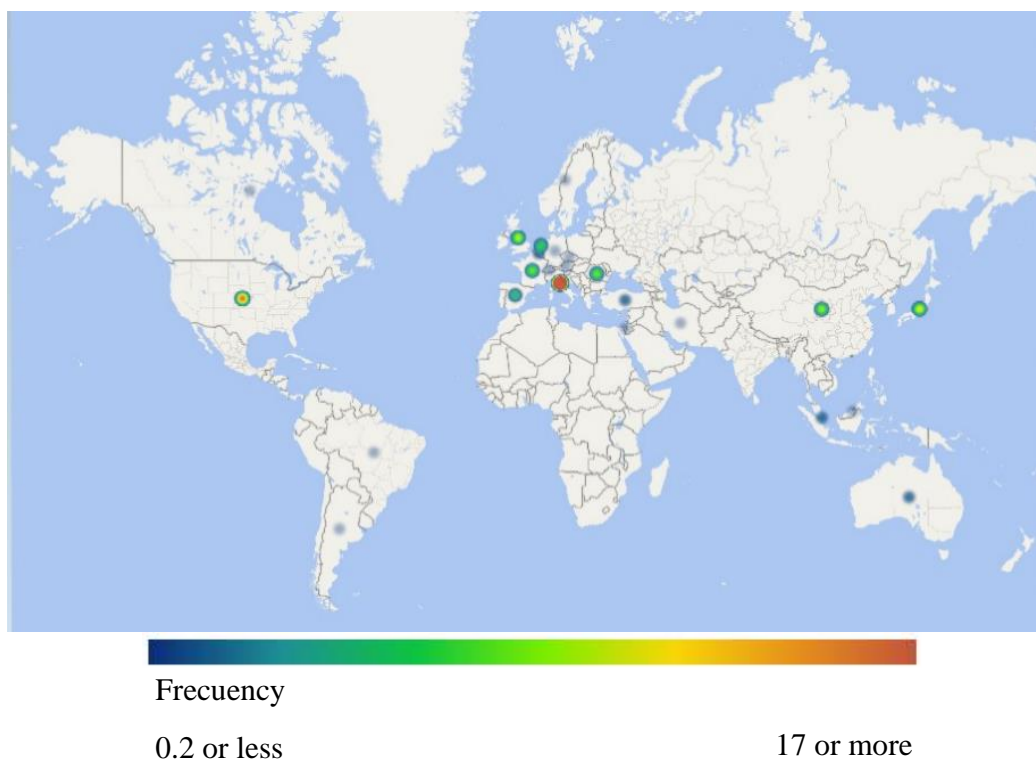

Table 1.

Number of documents published document type

\begin{tabular}{cc}
\hline $\begin{array}{c}\text { Document } \\
\text { type }\end{array}$ & Documents \\
\hline Technical & $1(1 \%)$ \\
communication & \\
Review article & $8(4 \%)$ \\
Research & $115(61 \%)$ \\
article & $1(1 \%)$ \\
Preface & $1(1 \%)$ \\
Encyclopedia & $4(2 \%)$ \\
Editorial & $1(1 \%)$ \\
Description & $27(14 \%)$ \\
Conference \\
paper & $31(16 \%)$ \\
Book chapter &
\end{tabular}

Figure 3. Map of distribution of investigations carried out

Among the results obtained, it was found that the number of investigations involving Natech hazards has varied over time. From the year 2000 to 2003 there were no publications related to the topic. Figure 4 shows that with time, interest in having an understanding of Natech events has increased, with 2017 being the year with most publications. This behavior is because the concern for technological disasters triggered by natural disasters in densely populated and industrialized areas is growing (Cruz \& Okada, 2008). On the other hand, requirements governing prevention of chemical accidents triggered by natural disasters (Seveso III Directive) in the European Union (EU) have generated concern about having plans to prevent and mitigate industrial risks derived from Natech events (Krausmann, Fendler, Averous-Monnery, Cruz, \& Kato, 2017). All in all, the increase in the number of investigations in Natech events suggests the need to include the risk derived from natural events in risk management at the industrial level.

Figure 5 presents the types of documents found in the literature review. In peer reviewed journals predominate in the publications found, followed by book chapters, and conference papers. Within the research articles, $37 \%$ involved descriptive analysis, and 37\% involved quantitative analysis.

Technical communications are essential because they present evidence that serves to support or identify parameters or variables of methods or methodologies that can be improved. For instance, (Mara, Tanasescu, Ozunu, \& Vlad, 2007) issued a technical communication in which they identify the main advantages of a standard methodology for the identification and quantification of risk concerning the environmental impact of accidents in dams waste. 


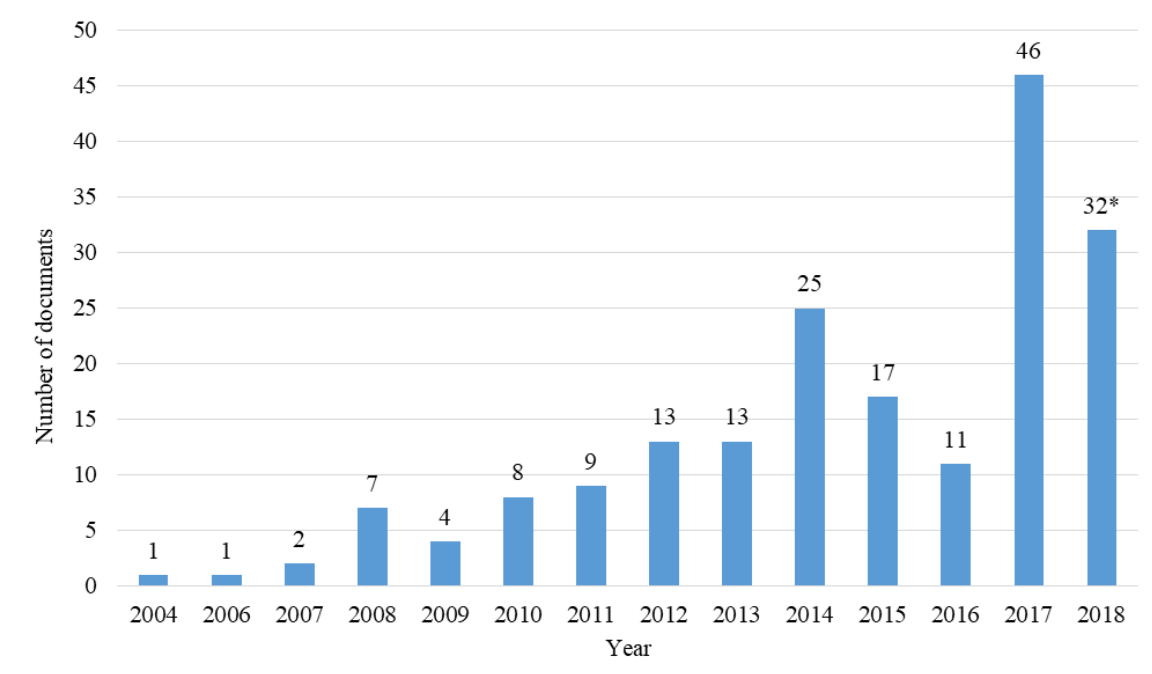

Figure 4. Number of publications per year

*Review of the literature until December 2018

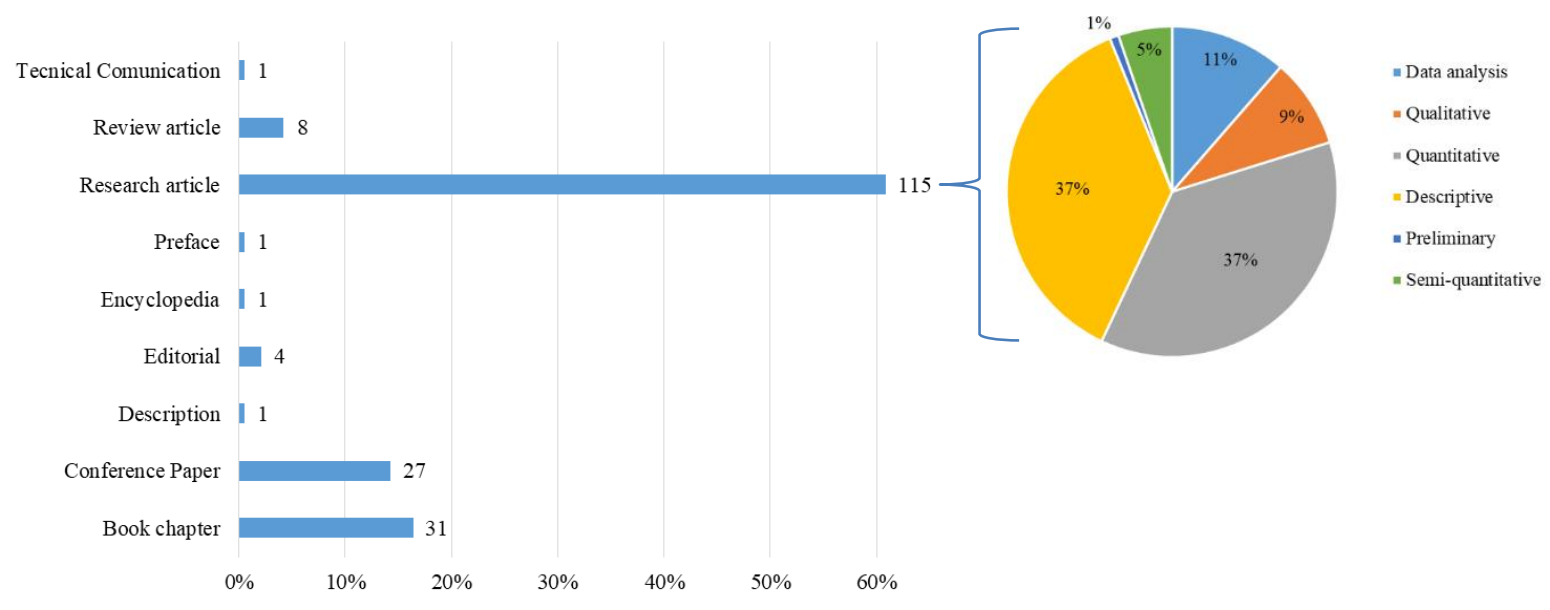

Figure 5. Document type

Furthermore, the review articles provide a clear picture of a specific topic with the purpose of knowing the threshold of knowledge in that topic. Within the review articles found, (Young, Balluz, \& Malilay, 2004) made a description of examples of natural disasters that involved the releases of chemical substances, and their consequences on public heal and the environment. This review is complemented by the one made by (Al-shanini, Ahmad, \& Khan, 2014), who presented a review of accident models that have been developed for the chemical process industry, and advised that the future direction of these accidental models will be the addition of natural hazards in their analysis to minimize consequences in an eventual Natech accident. In addition, (Steinberg, Sengul, \& Cruz, 2008) discussed the state of the art for risk and Natech management, taking as an example the consequences of hurricanes such as Katrina and Rita, and concluding that the population, being one of the agents most impact by Natech events, should participate in a comprehensive discussion of acceptable risks for this type of events. Subsequently, (Necci, Cozzani, Spadoni, \& Khan, 2015) presented an essential focus on Natech risk because they included the domino effect 
in a systematic review, from which they concluded that there is no consistent agreement on the evaluation processes to address the escalation risk that results in domino effect scenarios. Finally, (Nascimento \& Alencar, 2016) presented a general review of Natech events, providing relevant information from pioneering journals on risk issues, precursor institutions at Natech events, and main contributions made by researchers. To summarize, the literature reviews showed a focus on relevant topics that complement each other to find the progress in Natech methodologies and risk analysis.

As mentioned above, at the level of research articles, descriptive, and quantitative analyses predominate, and this is a trend that is repeated under the type of analysis level (see Figure 6). Descriptive analyses represent $49 \%$ of the publications, and an essential part of these focus on the analysis of past Natech events.

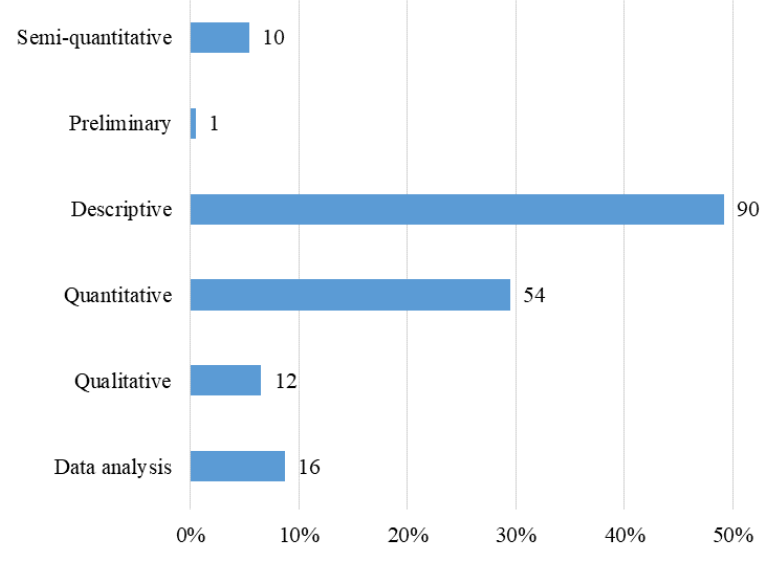

Figure 6. Type of analysis

The results in descriptive analysis and data analysis are highlighted below. In total, 90 documents were classified as descriptive and 16 documents as data analysis.

Table 2.

Number of documents published by type of Natech event trigger

\begin{tabular}{ccc}
\hline $\begin{array}{c}\text { Natural event triggering a } \\
\text { technological disaster }\end{array}$ & \multicolumn{2}{c}{ Type of analysis } \\
Descriptive & Data analysis \\
\hline Lightning & 6 & 4 \\
Strong winds & 4 & 3 \\
Torrential rains & 5 & 3 \\
Tornadoes & 2 & 3 \\
Storms & 6 & 3 \\
Hurricanes & 7 & 3 \\
Floods & $\mathbf{1 4}$ & $\mathbf{5}$ \\
Tsunamis & 8 & 2 \\
Droughts & 1 & 1 \\
Earthquakes & $\mathbf{1 9}$ & $\mathbf{9}$ \\
Landslides & 7 & 2 \\
Wildfires & 3 & 0 \\
\hline
\end{tabular}




\begin{tabular}{ccc}
\hline $\begin{array}{c}\text { Natural event triggering a } \\
\text { technological disaster }\end{array}$ & \multicolumn{2}{c}{ Type of analysis } \\
Descriptive & Data analysis \\
\hline Extreme temperatures & 2 & 3 \\
Snowfalls & 2 & 1 \\
Avalanches & 1 & 0 \\
volcanic eruptions & 3 & 0 \\
Dam failures & 1 & 0 \\
Tailings ponds & 1 & 0 \\
Salt Mine Collapsing Sinkhole & 1 & 0 \\
Cyclones, typhoons, others & 1 & 0 \\
\hline
\end{tabular}

As shown in Table 2, Natech events caused by earthquakes and floods encompass the majority of descriptive documents and data analysis developed. In the first instance, most of the research in Natech events have been carried out in European Union countries primarily Italy, but also France, Holland, and Romania. The most significant number of research centers dedicated to this topic are in Italy (Nascimento \& Alencar, 2016), that has suffered consequences from some earthquakes, which explains the frequency of research and analysis in this type of event. On the other hand, the second country with the highest contribution in research of Natech events is the United States (Nascimento \& Alencar, 2016), which in recent years has suffered the consequences of floods left by the passage of hurricanes such as Katrina and Rita. These events have resulted in multiple documents that address the issue with case studies, data analysis, description of events, quantification of consequences, and so on, with what is explained the frequency of research and analysis in floods. All of these descriptive and data analysis documents represent the effort of the scientific community to address the issue of Natech events from studying events that have occurred.

Each analysis methodology or mathematical model is focused on one or some specific natural events. Within the present literature review, it was found that the natural events (that cause most Natech accidents) with the most research are earthquakes, floods, and lightning, respectively. The following is the number of investigations implicit in a model or methodology (preliminary, qualitative, semi-quantitative, or quantitative) by type of natural event.

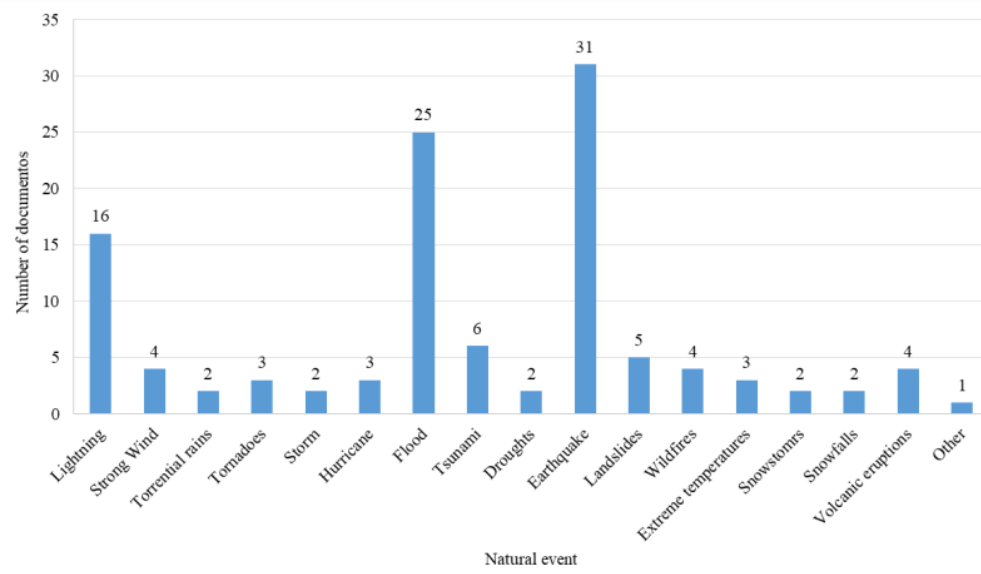

Figure 7. Number of researches of preliminary, qualitative, semiquantitative, or quantitative type by type of Natech event trigger 
The events with less research correspond to less frequent events such as cyclones and dam failures. The Natech events are considered HILP scenarios causing strong concern (Cozzani et al., 2014); however, in recent decades, events such as earthquakes, floods, lightning, hurricanes, storms, torrential rains, landslides, tornadoes, and strong winds have increased in probability of occurrence, creating more need for research (see Figure 1).

Regarding the type of analysis developed for each Natech event, it was found that quantitative analyses predominate compared to qualitative and semi-quantitative analyses, and the common natural hazard triggering events in the three types of analysis (qualitative, semi-quantitative, and quantitative) correspond to earthquakes and floods.

For preliminary analyses, (Cruz \& Okada, 2008) proposed a methodology for the preliminary assessment of Natech risk in urban areas. This methodology was designed to be used by local government officials in consultation with the population, and it considers possible interactions between different systems in the urban environment: physical infrastructure (industrial plants, lifeline systems, and critical installations), community (exposed population), environment, risk, and emergency management systems. In addition, factors related to vulnerability and hazard are analyzed, and qualitative measures are recommended. As a case study to validate the methodology, the data of the hazardous materials emissions during the Kocaeli earthquake, in Turkey on August 17th of 1999, were used. The limitations of the proposed methodology are discussed, as well as future research needs. This methodology is an easy tool to use and understand for non-technical staff; however, one of the main limitations is that its scope reaches Natech risk detection without replacing the complete Natech risk assessment, which requires the participation of experts. Additionally, due to its qualitative nature, the detected Natech risk index (NRI) serves only for comparison purposes between storage locations of hazardous materials, and they are not absolute values of the Natech risk of a territory (Cruz \& Okada, 2008).

Despite being a methodology that considers elements of vulnerability, it is limited to direct impacts on nearby storage tanks, residents who live within the exposed areas, and the built environment. The direct impacts on the environment are considered superficially, and the economic consequences are not within this scope. Additionally, the NRI values are estimated for individual storage tanks containing hazardous materials. These conditions create a problem since community members and government officials often do not have access to detailed information on all chemicals stored in industrial plants in their territory. Therefore, in these cases, the results may underestimate the true Natech risk (Cruz \& Okada, 2008). (Krausmann, Köppke, Fendler, Cruz, \& Girgin, 2017) summarized this methodology and presents the mathematical models used.

Concerning qualitative analyses, the documents found present an approach related to Natech risks for lightning, floods, and earthquakes. In the first instance (Krausmann \& Mushtaq, 2008) used a methodology that investigates the risk associated with flooding of industrial facilities by analyzing historical cases and applying expert judgment. The method includes a qualitative classification of historical floods for different industries, identifying types of emissions, damages, and so on. As the main product of the research, the authors developed a qualitative scale that relates the severity of the floods to the potential general and industry damage. However, although it is a methodology that has a qualitative scope, the subjectivity in the assumptions increases the uncertainty of the results. This methodology could be complemented with the quantification of the damage scale presented, but this 
depends on the existence of an exhaustive quantity of quantitative information for the severity of Natech events. Subsequently, (E. Renni, A. Basco, et al., 2010) developed a general framework for the Natech risk assessment. The authors carried out an analysis of historical accident data that allowed them to consolidate data from the analyzed process equipment affected by floods, lightning, and earthquakes. Through this methodology, the authors identified failure modes and damage states in storage tanks caused by lightning, earthquakes, and flooding, and they obtained the estimated value of LOC intensity.

In the year 2011, (Busini, Marzo, Callioni, \& Rota, 2011) developed a qualitative methodology for the initial assessment of earthquake risk, as a screening tool to identify in which situations a QRA is required. The proposed methodology is based on three models developed under the hierarchical analytical process where the hierarchies include fires, toxic dispersion, and explosions. One of the advantages of the model is that it requires few resources and information about the plant and the expected earthquake, so it would be suitable for any stage within the life cycle of the facilities; however, the hierarchical analytical process requires an adequate qualification of the hierarchies by means of the Saaty scale, with the participation of experts in the areas studied, or else either the weights of the hierarchies invalidate the procedure or the results obtained would present errors. Complementing this work, (E. Salzano et al., 2013) conducted a qualitative risk analysis for lightning, flood, and earthquake events using the models developed under the hierarchical analytical process presented by (Busini et al., 2011). The analyses allowed the application of a methodology already designed for other Natech events.

In this same year, (Krausmann et al., 2011) described the ongoing efforts in the development of new concepts and tools for the ranking of hazards and vulnerability of Natech events, risk assessment, risk-based design, and emergency planning and early warning, taking into account lightning, floods, and Earthquake events. The framework presented starts with used for the risk analysis of process plant induced by natural events submitted by (E. Renni, A. Basco, et al., 2010), and continues with the presentation of a ranking of hazard and vulnerability depending on the intensity of the earthquake (adopted by the Global Seismic Hazard Assessment Program). The framework suggests carrying out a quantitative assessment of risks, then proposes a risk-based design, and ends with the preparation of an emergencies plan. This framework suggests a complete analysis taking into account that it frames qualitative and quantitative aspects. After this work, (C. El Hajj et al., 2012) designed bow-tie diagrams to perform risk analysis in facilities that are vulnerable to flooding. These bow-tie diagrams were designed as the first step of a three-step methodology that consists of a checklist used to reduce the vulnerability of industrial facilities to lightning, earthquake, and flood events. Taking into account the methodology of bow-tie diagrams, the main difficulty of the method is to correctly identify the initiating events to develop the event trees and to determine the consequences for developing the consequence trees adequately.

(Necci, Argenti, Landucci, \& Cozzani, 2014) developed a methodology for the evaluation of final results after lightning in an atmospheric storage tank containing flammable liquids. In particular, the authors identified reference scenarios and mitigation barriers that can influence the sequences of events after the impact of the lightning. Subsequently, they obtained the trees of reference events and validated those using data from past accidents and, with the evaluation of standard safety barriers applied in industrial practice, quantified the event trees based on generic reference values for the probability of failure under demand. The results obtained under this methodology provide useful data to support and extend the qualitative and quantitative assessment of the risk caused by the main 
factors induced by lightning. Then, (Carine El Hajj et al., 2015) developed a systematic methodology for risk analysis that resulted in proposing general bow-tie diagrams that reconfigure accidental scenarios caused by floods. The authors suggested a risk analysis based on the definition of objectives, continuing with the identification of risks and hazards, and ending with the identification of risk mechanisms or accident scenarios; however, the analysis is limited to identifying risks without going further. Taking into account the scope of the methodology, for future work, there is an opportunity to deepen the risk assessment (with an adequate selection of evaluation criteria for its prioritization) and in the control of risks (with the appropriate choice of control barriers, implementation, and monitoring).

Finally, the following are documents that refer to qualitative data but that do not include methodologies of analysis or methods: (a) (Paolacci, Giannini, \& De Angelis, 2013) presented a synthesis of the effects of earthquakes on the different types of process components where the most appropriate innovative seismic protection systems are recognized, but a risk analysis methodology is not presented; (b) (Lanzano et al., 2013) presented fragility curves, and PGV (Peak Ground Velocity) cut-off values for gas pipelines that can be used as a simple model for the QRA and land use planning (LUP); (c) (Casson Moreno, Guglielmi, \& Cozzani, 2018) applied a specific methodology (DyPASI Dynamic procedure for the identification of hazards) with which they identified the critical reference events and the chains of causes and consequences. The results were used to determine a set of safety barriers for the prevention and mitigation of accidents in the production and biogas improvement facilities; (d) (Compagnoni, Curadelli, \& Ambrosini, 2018) analyzed the seismic performance of the base of steel tanks of wide and thin atmospheric storage isolated by sliding concave bearings (SCB). The performance study, conducted through shaking table tests in a vertical cylindrical steel tank model, allowed authors to quantitatively determine the efficiency of the SCB by analyzing two structural parameters: (a) splash height and (b) base cutting force. Six real soil movements with different characteristics were considered. The results show the effectiveness of SCB in the reduction of the values of base cutting force for all the studied cases without significantly affecting the splash displacements in comparison with the fixed base support.

Regarding semi-quantitative analyses, the documents found present an approach related to Natech risks for strong winds, floods, earthquakes, landslides, and extreme temperatures. The first computational tool designed to perform semi-quantitative risk analysis was presented by (Girgin \& Krausmann, 2012). The authors of this tool named it RAPID-N, and it allows a quick assessment and mapping of the Natech risk for earthquakes with minimal data entry. This software allows the calculation of parameters of natural risk in the site and an estimate of the site, the process equipment, and the properties of the substance. Also, conditional probabilistic relationships between damage states and possible Natech event scenarios can be specified and, for different process equipment, curves can be defined. Within the calculation methodology, RAPID-N has the following modules: (a) scientific tools, (b) natural hazards, (c) facilities and process equipment and (d) risk assessment; these allow a semi-quantitative evaluation of optimal risks for earthquakes in production facilities. A year later, the same authors (Girgin \& Krausmann, 2013) presented a framework for computational tool RAPID-N. Also, (Krausmann, Köppke, et al., 2017) exposed a series of semi-quantitative risk assessment methods such as RAPID-N and TRAS 310 AND TRAS 320. 
Considering the importance of cascade effects in natural events, (Kadri et al., 2014) presented a methodology to carry out risk assessments of the impacts of natural hazards on critical infrastructure through cascade effects analysis. The proposed methodology can be used to provide critical infrastructures with greater protection and limit/mitigate the magnitude of the damage caused by its failure. This analysis methodology has an essential contribution in the evaluation of critical infrastructure (CI) risks in the framework of cascade effect analysis (CEA) since it allows the identification of all sources of danger involving CI, primarily events that can cause failure of CI, and the sequences of accidents generated after that failure or destruction, taking into account the human and organizational factors and the interdependencies between CI and/or CI systems (components).

Additionally, (Marzo, Busini, \& Rota, 2015) developed and validated a methodology capable of introducing information that allows discriminating the output of the risk index (KRI) based on the human presence in the areas potentially affected by the Natech events (earthquakes trigger Natech accidents), in comparison with the independent results of QRA. The convergence of the KRI values obtained with this methodology with the values of potential life loss (PLL) resulting from QRA in all the case studies analyzed, supports the validity of the methodology developed. Within the calculation model, the authors use a key vulnerability indicator (KVI) that is calculated using the hierarchical analytical process, which requires the participation of technical authorities in the subject to minimize errors in the classification of weights. Another research highlighted by its methodological contribution is that of (Soto \& Renard, 2015), who suggested a methodology based on the geographic information system, where the risk parameters are combined qualitatively with the vulnerabilities of the exposed assets. The methodology is based on a process that uses geospatial operations and a specific semiology to provide an efficient mapping of global risk. This methodology could be applied to any territory, risk, and asset, to produce operational and useful knowledge of technological risk mapping due to floods.

On the other hand, (Tolo, Patelli, \& Beer, 2017) provided a new and general model for assessing the exposure risk of spent nuclear fuel stored in a facility subject to flood risk, investigating the potential and limitations of Bayesian networks in this field. The network models the interaction between extreme climatic conditions and technological installation, as well as the propagation of faults within the system itself, considering the dependencies between the different components and the occurrence of human error. The authors extensively describe a real-world application of the Sizewell B nuclear power plant in East Anglia, in the United Kingdom, together with the models and the data set used. The results are presented for three different time scenarios in which climate change projections have been adopted to estimate future risks. It should be noted that this methodology is not designed for Natech events; nevertheless, the application under Bayesian modeling allows experts to suggest an application of this methodology in Natech analysis.

In the last year, (Pilone \& Demichela, 2018) designed a semi-quantitative methodology on a local scale for floods, earthquakes, landslides, and extreme temperatures, developed to increase the effectiveness of LUP related to risk management, in particular about multiple risks affecting the same territory (multiple risks). The authors developed a semi-quantitative approach based on an index scale from 0 to 3, which is applied to measure both the impact of risks and the interaction of risks. The proposed approach proved to be able to identify and bring the aspects of multiple risks to the attention of the decision makers, constituting a risk guide that can be integrated with the existing planning instruments to improve the quality of the decisions risk-related. 
Finally, the most recent work in methods of semi-quantitative analysis was presented by (Olivar et al., 2018) who proposed a method for quantifying the risk associated with extreme winds, floods, and earthquakes in vertical storage tanks operating under atmospheric conditions. This method allowed the establishment of possible accidental scenarios, as well as the estimation of different probabilities of failure or loss due to the buckling of the roof, the loosening of the roof, the overturning or the sliding of the tank. It is a tool that takes into account the interaction of the aforementioned natural phenomena and the physical and mechanical characteristics of hydrocarbon storage tanks. Besides, the model evaluates the different types of losses through fragility curves and standardized Probit curves, which take into account the uncertainty of the variables involved. In addition, the method calculates the losses of dangerous material once the storage tank has failed, estimates the consequences of the loss of containment and finally evaluates the associated risk. This model can be used as a verification and validation tool for existing risk assessment models of new and existing tanks; also, it provides information on the operating conditions and design practices necessary to mitigate the risk in different types of natural phenomena.

In terms of quantitative analyses, the documents found present an approach related to Natech risks such as lightning, strong winds, torrential rains, tornadoes, storms, hurricanes, floods, tsunamis, droughts, earthquakes, landslides, fires, extreme temperatures, blizzards, avalanches, and volcanic eruptions, as shown in Figure 8.

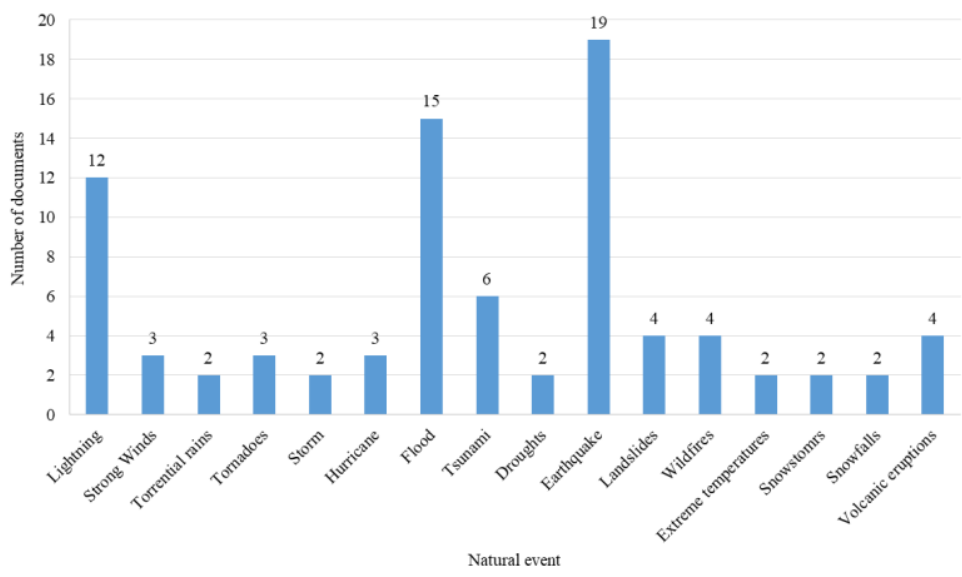

Figure 8. Quantitative analysis by type of event

The found methodologies that include quantitative analysis were classified taking into account the type of Natech event. In the first instance, for analysis of strong winds, torrential rains, tornadoes, storms, hurricanes, droughts, landslides, extreme temperatures, snow storms, and avalanches, 3 methodologies were found. On the one hand, (Chen, Chen, \& Li, 2012) presented a conceptual model of the evaluation of the process during the incident that reveals the possibility of a successful emergency response and the need to make response operations. The authors quantitatively analyzed three evaluation strategies: (a) mitigability (the measure of the degree to which an incident can be manually mitigated), (b) restructurability (the valuation of priority over the objects trapped in the victims' rescue process and saving the property after the incident), and (c) recoverability (the difficulty of restoring the affected functions to the basic operating state). This model aims to improve the 
management and emergency plans during an incident; therefore, no approach is specified for a particular Natech event as part of the concept of incident of any event that harms a population. In this model the Natech events mentioned are taken into account, but the events are not characterized. On the other hand, (Alvarado-Franco et al., 2017) presented a quantitative-mechanical model to evaluate the probability of failure in pipes due to their interaction with landslides. Their contribution includes the use of Monte Carlo simulations to calculate the probabilities of occurrence of landslides and faults in the pipeline at each analyzed point, and these probabilities are assigned to risk exposure levels using a linguistic scale. Finally, (Naderpour \& Khakzad, 2018) developed a Natech risk assessment methodology based on the capabilities of the Bayesian Network and takes into account possible domino effects. The methodology was implemented in a proposed refinery and mathematically represented the dynamic cause-effect relationships between the units involved in the scenario, with handling of uncertainties between the interactions. In addition, the proposed methodology provides a risk value for the entire scenario, which can be also used for decision making based on risk. The methodology includes the majority of parameters and variables of a quantitative risk analysis; however, the application of Bayesian networks in 7 of its steps indicates that the calculation of probabilities in each network must be done in a meticulous way to prevent generating subjectivities and to obtain real results.

In the case of earthquakes, 19 methodologies that include this event as general methodologies were found. First, (Antonioni, Spadoni, \& Cozzani, 2007) developed a procedure for the quantitative risk analysis for risk triggered by seismic events. This procedure included the synergy between the treatment of historical data and GIS tools to estimate the frequencies and severities of seismic events. The application of the methodology to some cases stuies showed that accident scenarios caused by seismic events can have a relevant influence on industrial risk. Second, (Campedel et al., 2008) developed a methodology for the quantitative assessment of the influence of external events on risk in industries. The methodology is based on vulnerability models of the main process equipment, and it presents the assessment of different simultaneous scenarios that may be derived from the impact of an external event in the process units. The general framework of the methodology, in principle, can be applied to the analysis of the impact of any external hazard in industrial plant systems, where hazardous materials exist. In this study, the methodology was applied to the Natech risk analysis caused by earthquakes in chemical and process plants. The authors analyzed the contributions of several scenarios derived from earthquakes on all industrial risk in three case studies, based on current layout plans of Italian refineries. In most cases, the results showed an increase in potential life loss (PLL) by at least an order of magnitude. Third, (Ernesto Salzano et al., 2009) developed a seismic risk analysis of industrial facilities where there were atmospheric storage tanks (anchored or not anchored to the ground), horizontal pressurized tanks, reactors, and pumps. The authors discussed simplified procedures and methodologies based on data from the historical database and the Natech literature for seismic risk assessment. In this way, specific fragility curves of the equipment were obtained based on a single earthquake measurement, the maximum acceleration of the ground (PGA). Fourth, (Antonioni, Bonvicini, Spadoni, \& Cozzani, 2009) developed specific methods and models to allow the quantitative assessment of the risk caused by two categories of Natech accidents: accidents triggered by earthquakes and accidents caused by floods. The approach allows the identification of the different damage modes expected for the process equipment and the accidental scenarios that can be triggered. 
The damage models developed allow authors to calculate the probability of damage to the elements of the equipment due to natural events. A specific methodology was developed to take into account the consequences of the possible simultaneous failure of several process units due to the impact of the natural event. The procedure allows the calculation of global indices of individual and social risk, including multiple failure scenarios caused by the impact of natural events.

In addition to the above, (Santella, Steinberg, \& Aguirra, 2011) calculated the probability of Natech occurrence due to hurricanes, earthquakes, tornadoes, and floods in the United States, using databases. These calculations showed a very variable Natech occurrence during single events, which indicates the presence of factors not quantified in this study. These results could inform risk analysis of Natech, help government agencies responsible for planning the response, plan remediation after a natural disaster, and should be useful in raising awareness about Natech risk in the industry. Instead, (Buratti, Ferracuti, Savoia, Antonioni, \& Cozzani, 2012) presented a procedure based on fuzzy numbers to model the uncertainty of the data in the quantitative analysis of risk assessment. The epistemic uncertainties about the seismic risk, obtained through the probabilistic analysis of the seismic hazard assessment, and the seismic fragility curves were modeled by the fuzzy set theory. This approach provides a very simple framework to threat uncertainties. In addition, (Gheorghiu, Torok, Ozunu, Antonioni, \& Cozzani, 2014) compared the results of individual risk (IR) and social risk (RS) between conventional technological risk and Natech risk, related to a possible Natech event triggered by an earthquake for two storage tanks for oil products, located in an urban area in the southeastern part of Romania. Another important work was developed by (Cozzani et al., 2014) who analyzed the application of different Natech risk models and Natech risk with domino effect by using several case studies. This was the first analysis that involved domino effect considering Natech events.

Other works related to earthquakes were developed by (Lanzano, Salzano, Santucci de Magistris, \& Fabbrocino, 2014) who analyzed the seismic vulnerability of buried pipelines that transport gas and liquid, the authors analyze a large amount of damage data from pipes collected from post-earthquake survey reports. The authors obtained seismic fragility formulations and threshold values for earthquake intensity with respect to the release of content from different types of pipes. In this way, they generated a new seismic evaluation tool that can cover the needs of the industrial risk assessment procedures and the land use planning requirements. They presented fragility and probit curves for pipes: they proposed a new performance indicator, compared to the existing fragility formulations for pipes that are based on a global repair rate and not on each individual damage mechanism analysis, and provided significant threshold values for seismic intensity parameters. (Meng et al., 2015) proposed a general methodology to assess the risks of loss of life introduced by hazardous chemical dispersion carried by air after seismically induced chemical release (induced SICR). (Bursi, Reza, Abbiati, \& Paolacci, 2015) described an experimental trial campaign conducted on a large-scale pipeline system to evaluate its seismic behavior. In particular, the authors tested a typical industrial pipe system, which contains several critical components, such as elbows, a bolted flange gasket and a T-joint, under different realistic earthquake load levels. (Urlainis, Shohet, \& Levy, 2015) developed a decision support tool for decision makers to evaluate and mitigate the risk of critical infrastructure after the occurrence of seismic events. The methodology analyzes the damage of the critical components of the infrastructure by Fault-Tree-Analysis, Decision Trees and Fragility Curves. (Hashimoto, Hata, \& Kawamura, 2017) conducted a numerical simulation of an oil spill by moving earth in storage tanks to 
estimate the volume spilled, which could generate significant fires in case of an earthquake in China. (Panico et al., 2017) carried out an analysis that allows calculating the vulnerability of wastewater treatment plants in the face of an earthquake, considering that an eventual dumping of this type of substance leads to important consequences in the environment. (Alessandri et al., 2017) proposed a new tool for the evaluation of the probabilistic seismic risk of process plants, based on Monte Carlo simulations. From the seismic risk curve of the site where the plant is located, they proposed a multi-level approach. (Bursi, di Filippo, La Salandra, Pedot, \& Reza, 2017) analyzed the probabilistic seismic demand of an LNG plant following the Performance Based Earthquake Engineering procedure. Under this methodology, they calculated failure problems for equipment, pipelines, and plant acessories. (Hosseini, Goudarzi, \& Soroor, 2017) proposed an innovative and practical method to reduce the movement of the floating roof during earthquakes, and the authors presented an experimental study, carried out by means of a vibrating table, to show the efficiency of this technique.

In the case of floods, 15 methodologies were found. The methodologies of (Antonioni et al., 2009), for earthquakes apply also to floods.

Furthermore, (Gai, Weng, \& Yuan, 2012) developed a risk assessment framework for natural and technological accidents for the quantitative analysis of risk of LOC accidents caused by floods. (Landucci, Antonioni, Tugnoli, \& Cozzani, 2012) developed a model to calculate the probability of damage to a vessel as a function of the severity of the flood. (Landucci, Tugnoli, Antonioni, \& Cozzani, 2013) developed a methodology for the determination of vulnerability models aimed at estimating the probability of equipment damage based on the severity or intensity of the flood parameters. In addition, they developed a mechanical model, based on the comparison between the flood intensity and the resistance of a ship and/or its support. (Tolo, Patelli, \& Beer, 2014) provided model Bayesian networks for the risk assessment of a spent nuclear fuel pond. The model was applied to three different scenarios of a real case study, which showed the high flexibility of Bayesian networks and their ability to adequately include climate change projections. (Landucci, Necci, Tugnoli, Antonioni, \& Cozzani, 2014) presented a vulnerability model for the evaluation of the probability of failure of atmospheric vessels involved in flood events. (Landucci, Necci, Antonioni, Tugnoli, \& Cozzani, 2014) developed and validated a mechanical damage model. Later, the authors obtained the simplified correlations to calculate the critical flood conditions that led to the failure of the container. In addition, using the framework of the QRA of the Natech scenarios caused by the floods, they proposed a fragility model for the direct evaluation of the probability of equipment damage in the.

Finally, (Cozzani et al., 2014) developed and applied a specific methodology for the implementation of the QRA of Natech events caused by floods, and the authors applied it to the evaluation of different flood events and equipment categories. The specific vulnerability models allowed authors to estimate the probability of failure of both the atmospheric and pressurized equipment, and the estimation of the release frequencies induced by Natech. (T. Liu, Zhang, Li, \& Li, 2017) designed a Bayesian Network to analyze the interaction between multiple subsystems, in which twenty-two variables were represented by nine root nodes, ten intermediate nodes and three leaf nodes. (Khakzad \& Van Gelder, 2017) developed a methodology for assessing the vulnerability of chemical facilities, particularly storage tanks above ground, which are subject to flooding. (Khakzad \& Van Gelder, 2018) developed a methodology based on physical reliability models and Bayesian networks to assess the fragility (probability of failure) of industrial plants to floods. 
In the case of lightning, 12 methodologies were found. Methodology by (Cozzani et al., 2014) for earthquakes and floods also applies to lightning. For complementing that, (E. Renni, M. Paolone, et al., 2010) presented an innovative procedure for the quantitative assessment of industrial risk due to LOC of hazardous substances triggered by lightning. The study focused on the development of models for the probability of impact of the beam and for the probability of damage. In particular, the authors developed a Monte Carlo approach to calculate the probability of a lightning strike based on the geometry of the structure and the intensity and intensity data of the rays. (Amos Necci et al., 2013) presented a quantitative methodology for assessing the probability of damage to storage tanks due to lightning. The severity of the beam was quantified by probability distribution functions of two parameters: maximum current intensity and lightning load. (A. Necci, G. Antonioni, E. Krausmann, et al., 2013) presented a detailed methodology for the evaluation of event trees quantified after the impact of lightning on an atmospheric tank. (Necci, Antonioni, Cozzani, Borghetti, \& Nucci, 2013) developed a statistical method to evaluate the frequency of tank failures due to lightning. The model includes both the evaluation of the beam impact probability and the conditional probability of tank damage given the impact of the beam. The method considers the effect of the lightning rods placed at given distances from the elements of the equipment and calculates the reduction of the failure frequency due to the competition of attraction between the rods and the equipment.

Finally, (Amos Necci, Giacomo Antonioni, et al., 2014) developed a specific model, based on Monte Carlo simulations, to evaluate the frequency of lightning capture for equipment with a specific geometry. The model allows the evaluation of the design effects and the reduction of the capture probability due to the presence of other structures or elements of equipment. The results of the Monte Carlo simulations were also used to develop a simplified cell method that allows an advance evaluation of the probability of beam impact in a framework of QRA. (Necci, Antonioni, Cozzani, Borghetti, \& Nucci, 2014) developed a dedicated methodology for QRA due to technological accidents caused by lightning in chemical and process industries. (Antonioni, Landucci, Necci, Gheorghiu, \& Cozzani, 2015) developed a methodology for the inclusion of accidents triggered by lightning in the QRA. The methodology was applied to several case studies of industrial interest that proved their effectiveness by allowing the calculation of individual and social risk due to accidents caused by lightning. (Yang, Chen, \& Chen, 2018) proposed a prediction method with the objective of evaluating the probability of a domino effect at different levels triggered by lightning in the chemical tank farm. The method the authors developed takes into account both the calculation model of fire probability triggered by a beam and the method of evaluating the probability of subsequent domino effect.

To summarize, in the literature consulted for Natech risk methodologies under a single hazard approach, events such as earthquakes, floods, and lightning present the largest number of studies, revealing the gap that exists in research for other types of Natech events. On the other hand, the quantitative analyses have attracted the greatest attention from the scientific community since they present the greatest number of methodologies developed.

\subsubsection{Analysis of publications based on multi-hazard analysis}

For publications based on multi-hazard analysis, 31 documents were found and analyzed. This number of documents is since (Gallina et al., 2016) published an article reviewing 
methodologies with a multi-hazard approach developed up to that moment, and for this reason, this document begins from that point until December 2018. Of the results obtained, $83 \%$ of the works are distributed in research articles, $2 \%$ in review article, $2 \%$ in conference papers, and $1 \%$ in technical communication (see Table 3 ).

Figure 9 presents the results of document type found in the literature review with a multihazard approach. Research articles predominate in the publications found, followed by conference papers, and review articles. Within the research articles, documents with quantitative analysis prevail with $57 \%$.

Table 3 .

Number of documents published by document type

\begin{tabular}{|c|c|c|}
\hline Document type & Documents & Authors \\
\hline Review article & $2(7 \%)$ & (Gallina et al., 2016), (Newman et al., 2017) \\
\hline Research article & $25(83 \%)$ & $\begin{array}{l}\text { (De Pippo et al., 2008), (Wipulanusat, Nakrod, \& Prabnarong, 2009), } \\
\text { (Mahendra, Prakash, Srinivasa Kumar, Shenoi, \& Shailesh, 2010), } \\
\text { (Lozoya, Sardá, \& Jiménez, 2011), (Kappes, Keiler, von Elverfeldt, \& } \\
\text { Glade, 2012), (Kappes, Gruber, et al., 2012), (Marzocchi, Garcia- } \\
\text { Aristizabal, Gasparini, Mastellone, \& Ruocco, 2012), (Kameshwar \& } \\
\text { Padgett, 2014), (Johnson, Depietri, \& Breil, 2016), (Gill \& Malamud, } \\
\text { 2017), (Stults, 2017), (Villegas-González, Ramos-Cañón, González- } \\
\text { Méndez, González-Salazar, \& De Plaza-Solórzano, 2017), (Bonacho \& } \\
\text { Oliveira, 2018), (Furlan, Torresan, Critto, \& Marcomini, 2018), } \\
\text { (Hagenlocher, Renaud, Haas, \& Sebesvari, 2018), (Hernández, Carreño, } \\
\text { \& Castillo, 2018), (Kwag \& Hahm, 2018), (K. Liu, Wang, Cao, Zhu, \& } \\
\text { Yang, 2018), (Mukherjee, Nateghi, \& Hastak, 2018), (Pilone \& } \\
\text { Demichela, 2018), (Reniers, Khakzad, Cozzani, \& Khan, 2018), (Sahoo \& } \\
\text { Bhaskaran, 2018), (Viavattene et al., 2018), (Zimmaro, Stewart, } \\
\text { Brandenberg, Kwak, \& Jongejan, 2018), (Zuccaro \& Leone, 2018) }\end{array}$ \\
\hline $\begin{array}{l}\text { Technical } \\
\text { communication }\end{array}$ & $1(3 \%)$ & (Nadim et al., 2013) \\
\hline $\begin{array}{l}\text { Conference } \\
\text { paper }\end{array}$ & $2(7 \%)$ & $\begin{array}{l}\text { (van Westen, Montoya, Boerbom, \& badilla Coto, 2002), (Bell \& Glade, } \\
\text { 2004) }\end{array}$ \\
\hline
\end{tabular}

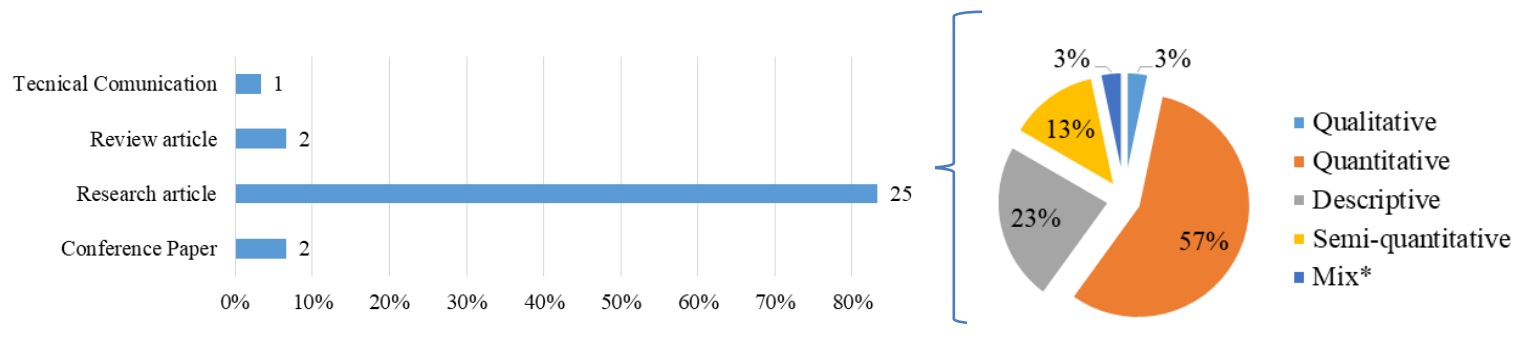

Figure 9. Document type. *Mix is a methodology which include qualitative, semi-quantitative, and quantitative analyses

As mentioned above, at the level of research articles, quantitative analyses predominate, and this is a trend that is repeated under the type of analysis level (see Figure 10). Descriptive analyses represent $23 \%$ of the 30 analyzed documents, and the other ones contain qualitative, 
semi-quantitative, and mixed analysis approaches (e.g., combining qualitative, semiquantitative and quantitative analyses).

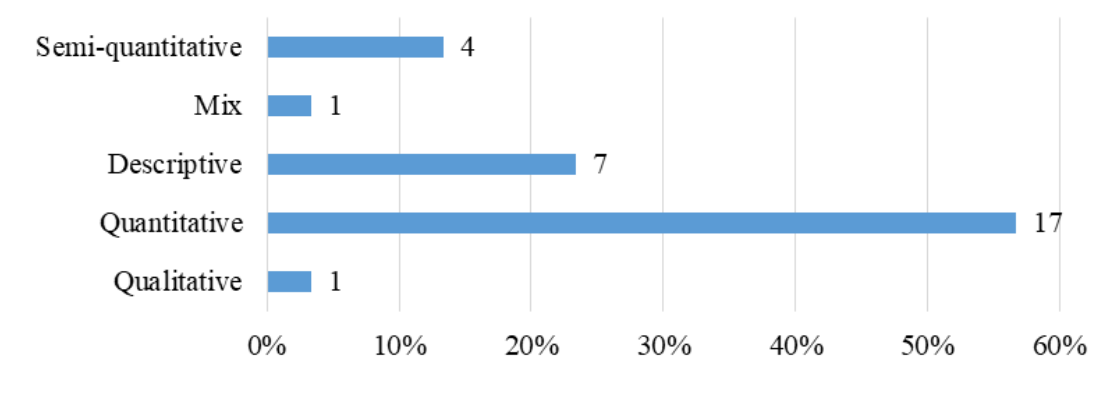

Figure 10. Type of analysis

In terms of qualitative analyses, (Gill \& Malamud, 2017) presented a broad overview, and a characterization and visualization of the role of 18 types of anthropogenic processes in the activation and influence of 21 natural hazards and the interactions of natural hazards. Although this work does not focus on Natech risk, its results highlight the interactions that may occur between the processes developed by man in a certain place and the natural events to which the population in that site are vulnerable to. In this case, the authors evaluated the interaction of some anthropogenic hazards with floods, earthquakes, landslides, and forest fires. The results obtained help the risk analysts to make decisions regarding the land use planning and with this the Natech risk could be prevented and reduced.

In terms of semi-quantitative analyses, 4 documents that refer to natural events with a multi-hazard approach were found. Within these analyses, (van Westen et al., 2002) conducted a case study using a multi-hazard methodology where they evaluated the individual risk of floods, earthquakes, and landslides events. Within the document, it is considered to be a multi-hazard analysis because they analyze the risk of 3 possible natural events that may affect the urban area under study. However, this type of analysis does not take into account the interaction of natural events or the chain reaction that may occur.

Nevertheless, (De Pippo et al., 2008) developed a semi-quantitative methodology with where the distribution of hazards in the coastal area of Campania (Italy) is quantified, classified, and mapped. The effect of single hazards in the area was evaluated. The multihazard analysis was carried out by means of an interaction matrix that allows experts to know if the natural events and the object of study present some interaction or not. For this case study, a multi-hazard analysis was performed for the interaction of natural events such as storms, floods, earthquakes, landslides, volcanic eruptions, and erosion.

Finally, in order to address the threats posed by climatic factors in combination with local and regional anthropogenic pressures affecting marine ecosystems and activities, (Furlan et al., 2018) developed a multiple hazard assessment methodology and applied it to Adriatic Sea for the reference scenario 2000-2015. In this analysis, the authors conducted an analysis focused on anthropogenic danger taking into account some natural hazards. Although this analysis is similar to the qualitative analysis presented by (Gill \& Malamud, 2017), the semiquantitative methodology presents fewer subjectivities. (Gill \& Malamud, 2017) presented a semi-quantitative methodology at local scale, developed to increase the effectiveness of land 
use planning related to risk management, particularly in relation to multiple risks that affect the same territory.

The 4 semi-quantitative analyses that were presented focus on minimizing risks in urban areas, that is, they do not have a Natech risk approach. However, methodologies such as the one proposed by (Gill \& Malamud, 2017) can have a significant contribution in the subject since they implicitly include the topic of land use planning, which goes hand in hand with the location of facilities and industrial parks.

In terms of quantitative analyses, 17 documents were found. First of all, (Bell \& Glade, 2004) developed a methodology to analyze natural risks for multiple processes. Landslide, snowfall, and debris flow events are taken into account. In this methodology, the risk was calculated as a function based on parameters of danger, vulnerability, probability of spatial impact, probability of temporary impact, probability of seasonal occurrence, and potential damage. Individual process risks are calculated and in the end each of the risks is combined within a multi-hazard risk map. It was concluded that the multi-hazard approaches are not only used to obtain a summary of the general risk, but also that they have a high significance in effectively planning countermeasures. This methodology applies to urban areas and does not have a Natech risk approach.

As in the previous case, (Wipulanusat et al., 2009) used a risk map to visualize and calculate the general risk caused by flood and drought events. A limitation of this type of methodology is that first the risk is analyzed individually for each natural event and in the end the overall risk is calculated. That is, the vulnerabilities are considered as static and their variation is not taken into account when the two events interact. The proposed methodology applies for analysis in urban areas without the Natech risk approach.

A variation of the two previous methodologies is the one proposed by (Mahendra et al., 2010). In this case, the author did not calculate the general risk with a risk map, but used vulnerability indexes throughout his methodology and finally obtained a vulnerability map for torrential rain and flood events in a coastal area. This type of analysis takes into account the variations of vulnerability of the place with respect to the types of natural events; however, it does not consider chain reactions. This methodology is applied to calculate risk in coastal areas without having a Natech risk approach.

In the literature review, most of the multi-hazard methodologies found do not consider Natech risks, and they are mentioned in chronological order as follows: (Lozoya et al., 2011) proposed a multi-hazard risk assessment for beaches in order to help policy and decision-making within the framework of integrated beach management processes for storm, flood, and erosion natural events. (Kappes, Gruber, et al., 2012) developed a regional multihazard exposure analysis concept for five natural hazards: floods, landslides, debris flows, and avalanches, complemented by a visualization scheme to present the modeling result. An automation of the two schemes resulted in a beta version of the MultiRISK modeling and the MultiRISK visualization software tool that make up the MultiRISK platform. (Kameshwar \& Padgett, 2014) presented a risk procedure based on parameterized fragility based on multiple risk assessment (PF-MHRA) for the evaluation of a portfolio of road bridges subjected to earthquake and hurricane events. (Johnson et al., 2016) presented the results of a GIS-based assessment of the current risk of socio-natural hazards in two socioeconomically distinct districts of Hong Kong (PRC) using indicators to describe the hazards and vulnerabilities of landslides, extreme temperature, and typhoons. (Bonacho \& Oliveira, 2018) proposed a way to combine the damage from the earthquake shake with the damage from the 
tsunami: the added damage. This is defined as an additive function. The added damage of a building is the sum of the damage caused by the earthquake plus those caused by the tsunami. (Hagenlocher et al., 2018) proposed an innovative approach based on a library of modular indicators for the assessment of the risk of multiple hazards of socio-ecological systems throughout the world and within the coastal deltas for storm, flood, drought, and cyclone events. (Hernández et al., 2018) evaluated hurricane risk for coastal cities through the definition of a system of indicators. Based on this indicator system, the Hurricane Risk Index (HRi) is calculated. This system allows the construction of vulnerability indexes for different dimensions: physical, environmental, social, economic, cultural, and institutional. The results obtained can contribute to the definition of public prevention policies and actions to reduce levels of vulnerability and increase the resistance of these communities. (Kwag \& Hahm, 2018) presented a practical approach to perform an earthquake-induced landslide probabilistic safety assessment (PSA) for nuclear units subject to earthquake and flood events. (K. Liu et al., 2018) provided a quantitative approach for assessing the susceptibility of a transport system subject to natural hazards on a relatively large scale, when subjected to natural events such as torrential rains, flood, landslides, and debris flow. (Mukherjee et al., 2018) proposed a multiple hazard approach to characterize the key predictors of sustained power outages induced by severe weather. With this, they developed a two-stage hybrid risk estimation model, taking advantage of algorithmic data extraction techniques for natural events such as strong winds, torrential rains, tornadoes, storm, hurricane, wildfires, and extreme temperature. (Sahoo \& Bhaskaran, 2018) attempted to investigate the physical, environmental, social, and economic impacts on the coastal vulnerability associated with tropical cyclones off the coast of Odisha. (Viavattene et al., 2018) analyzed how the Coastal Risk Assessment Framework (CRAF) has been developed as part of the Coastal Resilience Enhancement Strategies Toolkit (RISC-KIT). (Zimmaro et al., 2018) described and compared two reliability analysis frameworks of the dyke system for seismic and high water demands. (Zuccaro, De Gregorio, \& Leone, 2018) analyzed from a theoretical point of view the needs of modeling and the main problems that should be taken into account in the development of simulation tools with the aim of including cascade effect analysis to effectively support decision makers. This methodology takes into account the interaction of natural storm, flood, drought, earthquake, landslide, extreme temperature, volcanic eruption, and avalanche events.

In terms of mix analyses, within the literature consulted, a framework was found that includes three stages. The purpose of the authors (Nadim et al., 2013) was to develop a theoretical framework for a consistent assessment of multiple risks. In this framework, the first level is a qualitative flow diagram that guides the user to determine if a multiple risk approach is required for the problem in question. The second level is a simplified, semiquantitative approach to further explore the need for detailed evaluation. The third level is a quantitative analysis of multiple risks based on Bayesian networks. The key components of this framework are addressed, such as the assessment of cascading hazards, the estimation of time-dependent vulnerability and the choice of the required level of sophistication.

An important finding, which is presented as a common factor in the category of methodologies of analysis, is that all the found methodologies apply to a specific natural event in particular, and mostly apply for lightning, floods, and earthquakes. This means that, 
within the literature consulted, there are few methodologies that include the occurrence of 2 or more natural events happening simultaneously. This is because these kinds of events (multi-hazard events) have a low probability of occurrence; however, if the event occurs, there will be high impacts. In addition, a combination of Natech events triggered by landslide-avalanche, torrential rains-strong winds, and so on are multi-hazard events that have already occurred in the world, generating limitations in the available risk analysis and methodologies, but these events are generating new research opportunities in the scientific community. All in all, the evaluation of multi-hazard events is important depending on the frequency of occurrence that may happen, and the interaction between different events could be considered from the probabilistic analysis of historical databases that already take into account events that have occurred by chain reaction and cascade effect (databases of tsunamis caused by earthquakes).

\subsection{Industrial risk management}

Some industrial risk assessment methodologies take into account external factors such as natural events within their risk analysis. In the case of the American Petroleum Institute (API) the methodology proposed in API RP 581 (Risk-Based Inspection, RBI) for the Risk-Based Inspection (Institute, 2016) in process facilities, it only considers the frequency of earthquakes within the threat of climate and external forces. With the above, a gap is identified in this methodology since within the risk assessment of the assets of a facility in the Oil and Gas sector natural events are not being considered as tangible hazards. Nevertheless, API RP 752 (Management of Hazards Associated with Location of Process Plant Permanent Buildings) (Institute, 2009) provides additional guidance to companies operating in facilities covered by the OSHA PSM standard for proper management of risk taking into account explosions, fires and releases of toxic materials for new and existing buildings intended to be occupied. However, this recommended practice excludes storage facilities, since such facilities mainly store materials and are only occupied intermittently.

The American Institute of Chemical Engineers, Center for Chemical Process Safety (CCPS), is organization which identifies and addresses process safety needs in the chemical and pharmaceutical industries. CCPS publishes a series of guidance documents that are widely used in these industries. In the book Guidelines for Safe Storage and Handling of Reactive Materials (CCPS, 2010), this organization states that the storage of chemical substances creates the potential for hazards that include injury, disease, environmental damage, property damage, and business interruption, noting that natural disasters, including floods, can trigger these hazards. Moreover, CCPS has identified that floods have the potential to release chemicals into the environment. To understand the risk of flooding, companies are directed to Federal Emergency Management Agency (FEMA) resources, including the Flood Insurance Studies (FEMA, 2018) and Flood Insurance Rate Maps (FEMA, 2015).

Currently, in the United States, the consequences derived from Natech events are evaluated following the guidelines of the Risk Management Plan (RMP) (EPA, 2015), which has been assigned the methodology of the US EPA Risk Management Program. The results of this methodology are presented as summary reports and interactive risk maps. The tool can be used for land use and emergency planning.

The above are standards, guidance, and codes of practice developed by the United States institutions, and those documents address Natech risk briefly. In contrast to the United 
States approach, in the European Union, the risks of major chemical incidents are regulated by the Seveso Directive, which applies to industrial activities that use, handle or store specific hazardous substances. The Seveso III Directive requires that some facilities that manufacture or store large quantities of hazardous chemicals generate a safety report that demonstrates that the facility has a serious accident prevention policy and that incident scenarios have been identified and risks mitigated. In addition, this directive requires that facilities address the increased risk derived from the geographical location of a plant. Over time and after a series of incidents, the European Union updated the Seveso Directive in 2012 to address extreme climate risks more explicitly. Currently, the Seveso III Directive requires companies to identify and regularly assess environmental hazards, such as floods and earthquakes, for the safety of the facility.

Finally, under a global perspective, within the Guiding Principles for Chemical Accident Prevention, Preparedness and Response (OECD, 2015), the OECD included an addendum in 2015 which addresses Natural Hazard Triggering Technological Accidents (Natech) Risk Management; and consists of a number of amendments to the Guiding Principles and of the addition of a new chapter providing more detailed guidance on Natech prevention, preparedness and response. It takes into account the results of the Workshop on Natural Hazards Triggering Technological Accidents (Natech) Risk Management held in 2012, in Dresden, Germany that was held under the auspices of the OECD Working Group on Chemical Accidents (WGCA).

To sum up, it is evident that the efforts to include the assessment of risk derived from natural events in the industry have increased. Many governmental and non-governmental organizations have developed plans to include this type of risk in industrial plans to mitigate the consequences that may be triggered by the impact of a natural event. However, these efforts must be increased in order to address all natural hazard events that may affect industrial installations and thus have plans for prevention and mitigation of effects on surrounding the population and the environment.

\section{Conclusions}

The purpose of this study was to develop a systematic analysis of the literature related to the Natech risks, between 2000 and 2018, and taking as a categorization of the literature the type of document, type of analysis and type of Natech event. Taking into account the results obtained, it can be concluded that there is a great research opportunity from a single hazard risk approach related to Natech hazards caused by strong winds, torrential rains, storms, droughts, landslides, extreme temperatures, snowfalls, avalanches, and multiple events; since they do not present methodologies of preliminary, qualitative, and semi-quantitative analysis. On the other hand, natural events such as earthquakes, floods, and lightning strikes reach most of the documents consulted, with important results regarding qualitative, semiquantitative and quantitative analysis in the production facilities.

On the other hand, there are limitations in risk analysis methodologies with a multihazard approach for Natech events since the methodologies found focus on the prevention and mitigation of consequences in urban areas and not on industrial facilities. Additionally, all the multi-hazard methodologies analyzed handle static vulnerabilities, which means that the interaction of natural events is not taken into account, but natural events are analyzed individually. 
Finally, some industrial management methodologies were found that take into account the Natech events within the facilities. Entities such as the API, CCPS, EPA, FEMA, and OCDE have made an effort to incorporate the analysis of natural events as real dangers in their methodologies.

It is important to clarify that the results of this literature review is limited by the methodology presented by the Figure 2, so it could be possible that some works that do not use the term Natech are missing.

\section{Acknowledgment}

This work has been carried out at the Grupo de Investigación de Diseño de Productos y Procesos (GDPP) of the Universidad de los Andes and at the Centro de Estudios del Riesgo Tecnológico (CERTEC) of the Universidad Politécnica de Cataluña, under the patronage of Colciencias through the 785 call for the training of national researchers in doctoral studies. For this reason, we want to thank these three institutions for their advice and sponsorship in the development of this research.

\section{References}

Al-shanini, A., Ahmad, A., \& Khan, F. (2014). Accident modelling and analysis in process industries. Journal of Loss Prevention in the Process Industries, 32, 319-334. doi:https://doi.org/10.1016/j.jlp.2014.09.016

Alessandri, S., Caputo, A. C., Corritore, D., Giannini, R., Paolacci, F., \& Phan, H. N. (2017). Probabilistic risk analysis of process plants under seismic loading based on Monte Carlo simulations. Journal of Loss Prevention in the Process Industries. doi:https://doi.org/10.1016/j.jlp.2017.12.013

Alvarado-Franco, J. P., Castro, D., Estrada, N., Caicedo, B., Sánchez-Silva, M., Camacho, L. A., \& Muñoz, F. (2017). Quantitative-mechanistic model for assessing landslide probability and pipeline failure probability due to landslides. 222(Supplement C), 212-224.

Antonioni, G., Bonvicini, S., Spadoni, G., \& Cozzani, V. (2009). Development of a framework for the risk assessment of Na-Tech accidental events. Reliability Engineering \& System Safety, 94(9), 1442-1450. doi:https://doi.org/10.1016/j.ress.2009.02.026

Antonioni, G., Landucci, G., Necci, A., Gheorghiu, D., \& Cozzani, V. (2015). Quantitative assessment of risk due to NaTech scenarios caused by floods. Reliability Engineering \& System Safety, 142, 334-345. doi:https://doi.org/10.1016/j.ress.2015.05.020

Antonioni, G., Spadoni, G., \& Cozzani, V. (2007). A methodology for the quantitative risk assessment of major accidents triggered by seismic events. Journal of Hazardous Materials, 147(1), 48-59. doi:https://doi.org/10.1016/j.jhazmat.2006.12.043

Arnold, M., Chen, R., Deichmann, U., Dilley, M., Lerner-Lam, A., Pullen, R., \& Zoe, T. (2006). Natural Disaster Hotspots Case Studies: World Bank.

Bell, R., \& Glade, T. (2004). Multi-Hazard Analysis in Natural Risk Assessments. Paper presented at the International Conference on Computer Simulation in Risk Analysis and Hazard Mitigation Rhodes, Greece.

Bonacho, J., \& Oliveira, C. S. (2018). Multi-hazard analysis of earthquake shaking and tsunami impact. International Journal of Disaster Risk Reduction, 31, 275-280. doi:https://doi.org/10.1016/j.ijdrr.2018.05.023

Buratti, N., Ferracuti, B., Savoia, M., Antonioni, G., \& Cozzani, V. (2012) A fuzzy-sets based approach for modelling uncertainties in quantitative risk assessment of industrial plants under seismic actions. In: Vol. 26. Chemical Engineering Transactions (pp. 105-110).

Bursi, O. S., di Filippo, R., La Salandra, V., Pedot, M., \& Reza, M. S. (2017). Probabilistic seismic analysis of an LNG subplant. Journal of Loss Prevention in the Process Industries. doi:https://doi.org/10.1016/j.jlp.2017.10.009 
Bursi, O. S., Reza, M. S., Abbiati, G., \& Paolacci, F. (2015). Performance-based earthquake evaluation of a full-scale petrochemical piping system. Journal of Loss Prevention in the Process Industries, 33, 1022. doi:https://doi.org/10.1016/j.jlp.2014.11.004

Busini, V., Marzo, E., Callioni, A., \& Rota, R. (2011). Definition of a short-cut methodology for assessing earthquake-related Na-Tech risk. Journal of Hazardous Materials, 192(1), 329-339. doi:10.1016/j.jhazmat.2011.05.022

Campedel, M., Cozzani, V., Garcia-Agreda, A., \& Salzano, E. (2008). Extending the quantitative assessment of industrial risks to earthquake effects. Risk Analysis, 28(5), 1231-1246. doi:10.1111/j.15396924.2008.01092.x

Casal, J. (2018). Chapter 1 - Introduction. In J. Casal (Ed.), Evaluation of the Effects and Consequences of Major Accidents in Industrial Plants (Second Edition) (pp. 1-24): Elsevier.

Casson Moreno, V., Guglielmi, D., \& Cozzani, V. (2018). Identification of critical safety barriers in biogas facilities. Reliability Engineering \& System Safety, 169, 81-94. doi:https://doi.org/10.1016/j.ress.2017.07.013

CCPS. (2010). Guidelines for Safe Storage and Handling of Reactive Materials (J. W. Sons Ed.): Wiley.

Chakraborty, A., Ibrahim, A., \& Cruz, A. M. (2018). A study of accident investigation methodologies applied to the Natech events during the 2011 great east Japan earthquake. Journal of Loss Prevention in the Process Industries. doi:https://doi.org/10.1016/j.jlp.2018.01.003

Chen, A., Chen, N., \& Li, J. (2012). During-incident process assessment in emergency management: Concept and strategy. Safety Science, 50(1), 90-102. doi:https://doi.org/10.1016/j.ssci.2011.07.006

Compagnoni, M. E., Curadelli, O., \& Ambrosini, D. (2018). Experimental study on the seismic response of liquid storage tanks with Sliding Concave Bearings. Journal of Loss Prevention in the Process Industries, 55, 1-9. doi:https://doi.org/10.1016/j.jlp.2018.05.009

Cozzani, V., Antonioni, G., Landucci, G., Tugnoli, A., Bonvicini, S., \& Spadoni, G. (2014). Quantitative assessment of domino and NaTech scenarios in complex industrial areas. Journal of Loss Prevention in the Process Industries, 28, 10-22. doi:https://doi.org/10.1016/j.jlp.2013.07.009

Cruz, A. M., \& Krausmann, E. (2013). Vulnerability of the oil and gas sector to climate change and extreme weather events. Climatic Change, 121(1), 41-53. doi:10.1007/s10584-013-0891-4

Cruz, A. M., \& Okada, N. (2008). Methodology for preliminary assessment of Natech risk in urban areas. Natural Hazards, 46(2), 199-220. doi:10.1007/s11069-007-9207-1

Cruz, A. M., Steinberg, L. J., \& Vetere-Arellano, L. (2006). Emerging issues for natech disaster risk management in Europe. Journal of Risk Research, 9(5), 483-501. doi:10.1080/13669870600717657

De Pippo, T., Donadio, C., Pennetta, M., Petrosino, C., Terlizzi, F., \& Valente, A. (2008). Coastal hazard assessment and mapping in Northern Campania, Italy. Geomorphology, 97(3), 451-466. doi:https://doi.org/10.1016/j.geomorph.2007.08.015

El Hajj, C., Piatyszek, E., \& Laforest, V. (2012). Development of generic scenarios of industrial accidents triggered by floods: A first step toward decreasing the vulnerability of industrial facilities. Paper presented at the WIT Transactions on Information and Communication Technologies.

El Hajj, C., Piatyszek, E., Tardy, A., \& Laforest, V. (2015). Development of generic bow-tie diagrams of accidental scenarios triggered by flooding of industrial facilities (Natech). Journal of Loss Prevention in the Process Industries, 36, 72-83. doi:https://doi.org/10.1016/j.jlp.2015.05.003

EPA. (2015). Risk Management Plan (RMP) Rule. In. United States: US Environmental Protection Agency.

FEMA. (2015). Flood Insurance Rate Maps. In.

FEMA. (2018). Flood Insurance Studies In.

Furlan, E., Torresan, S., Critto, A., \& Marcomini, A. (2018). Spatially explicit risk approach for multi-hazard assessment and management in marine environment: The case study of the Adriatic Sea. Science of The Total Environment, 618, 1008-1023. doi:https://doi.org/10.1016/j.scitotenv.2017.09.076

Gai, C., Weng, W., \& Yuan, H. (2012). Quantitative risk assessment of LOC accidents triggered by floods. Qinghua Daxиe Xиebao/Journal of Tsinghua University, 52(11), 1597-1600.

Gallina, V., Torresan, S., Critto, A., Sperotto, A., Glade, T., \& Marcomini, A. (2016). A review of multi-risk methodologies for natural hazards: Consequences and challenges for a climate change impact assessment. Journal of Environmental Management, 168, 123-132. doi:https://doi.org/10.1016/j.jenvman.2015.11.011

Gheorghiu, A. D., Torok, Z., Ozunu, A., Antonioni, G., \& Cozzani, V. (2014). COMPARATIVE ANALYSIS OF TECHNOLOGICAL AND NATECH RISK FOR TWO PETROLEUM PRODUCT TANKS 
LOCATED IN SEISMIC AREA. Environmental Engineering and Management Journal, 13(8), 18871892.

Gill, J. C., \& Malamud, B. D. (2017). Anthropogenic processes, natural hazards, and interactions in a multihazard framework. Earth-Science Reviews, 166, 246-269. doi:https://doi.org/10.1016/j.earscirev.2017.01.002

Girgin, S., \& Krausmann, E. (2012) Rapid natech risk assessment and mapping tool for earthquakes: Rapid-n. In: Vol. 26. Chemical Engineering Transactions (pp. 93-98).

Girgin, S., \& Krausmann, E. (2013). RAPID-N: Rapid natech risk assessment and mapping framework. Journal of Loss Prevention in the Process Industries, 26(6), 949-960. doi:https://doi.org/10.1016/j.jlp.2013.10.004

Hagenlocher, M., Renaud, F. G., Haas, S., \& Sebesvari, Z. (2018). Vulnerability and risk of deltaic socialecological systems exposed to multiple hazards. Science of The Total Environment, 631-632, 71-80. doi:https://doi.org/10.1016/j.scitotenv.2018.03.013

Hashimoto, H., Hata, Y., \& Kawamura, K. (2017). Estimation of oil overflow due to sloshing from oil storage tanks subjected to a possible Nankai Trough earthquake in Osaka bay area. Journal of Loss Prevention in the Process Industries, 50, 337-346. doi:https://doi.org/10.1016/j.jlp.2016.10.008

Hernández, M. L., Carreño, M. L., \& Castillo, L. (2018). Methodologies and tools of risk management: Hurricane risk index (HRi). International Journal of Disaster Risk Reduction, 31, 926-937. doi:https://doi.org/10.1016/j.ijdrr.2018.08.006

Hosseini, M., Goudarzi, M. A., \& Soroor, A. (2017). Reduction of seismic sloshing in floating roof liquid storage tanks by using a Suspended Annular Baffle (SAB). Journal of Fluids and Structures, 71, 4055. doi:https://doi.org/10.1016/j.jfluidstructs.2017.02.008

Institute, A. P. (2009). API RP 752 - Management of Hazards Associated with Location of Process Plant Permanent Buildings. In. Washington, D.C.: American Petroleum Institute.

Institute, A. P. (2016). API RP 581 - Risk-Based Inspection (RBI). In (3th ed.). Wanshington, D.C.: American Petroleum Institute.

Johnson, K., Depietri, Y., \& Breil, M. (2016). Multi-hazard risk assessment of two Hong Kong districts. International Journal of Disaster Risk Reduction, 19, 311-323. doi:https://doi.org/10.1016/j.ijdrr.2016.08.023

Kadri, F., Birregah, B., \& Chatelet, E. (2014). The Impact of Natural Disasters on Critical Infrastructures: A Domino Effect-based Study. Journal of Homeland Security and Emergency Management, 11(2), 217241. doi:10.1515/jhsem-2012-0077

Kameshwar, S., \& Padgett, J. E. (2014). Multi-hazard risk assessment of highway bridges subjected to earthquake and hurricane hazards. Engineering Structures, 78, 154-166. doi:https://doi.org/10.1016/j.engstruct.2014.05.016

Kappes, M. S., Gruber, K., Frigerio, S., Bell, R., Keiler, M., \& Glade, T. (2012). The MultiRISK platform: The technical concept and application of a regional-scale multihazard exposure analysis tool. Geomorphology, 151-152, 139-155. doi:https://doi.org/10.1016/j.geomorph.2012.01.024

Kappes, M. S., Keiler, M., von Elverfeldt, K., \& Glade, T. (2012). Challenges of analyzing multi-hazard risk: A review. Natural Hazards, 64(2), 1925-1958. doi:10.1007/s11069-012-0294-2

Khakzad, N., \& Van Gelder, P. (2017). Fragility assessment of chemical storage tanks subject to floods. Process Safety and Environmental Protection, 111, 75-84. doi:https://doi.org/10.1016/j.psep.2017.06.012

Khakzad, N., \& Van Gelder, P. (2018). Vulnerability of industrial plants to flood-induced natechs: A Bayesian network approach. Reliability Engineering \& System Safety, 169, 403-411. doi:https://doi.org/10.1016/j.ress.2017.09.016

Komendantova, N., Mrzyglocki, R., Mignan, A., Khazai, B., Wenzel, F., Patt, A., \& Fleming, K. (2014). Multihazard and multi-risk decision-support tools as a part of participatory risk governance: Feedback from civil protection stakeholders. International Journal of Disaster Risk Reduction, 8, 50-67. doi:https://doi.org/10.1016/j.ijdrr.2013.12.006

Krausmann, E., Cozzani, V., Salzano, E., \& Renni, E. (2011). Industrial accidents triggered by natural hazards: an emerging risk issue. Natural Hazards and Earth System Sciences, 11(3), 921-929. doi:10.5194/nhess-11-921-2011

Krausmann, E., \& Cruz, A. M. (2013). Impact of the 11 March 2011, Great East Japan earthquake and tsunami on the chemical industry. Natural Hazards, 67(2), 811-828. doi:10.1007/s11069-013-0607-0

Krausmann, E., \& Cruz, A. M. (2017). Chapter 2 - Past Natech Events. In E. Krausmann, A. M. Cruz, \& E. Salzano (Eds.), Natech Risk Assessment and Management (pp. 3-31): Elsevier. 
Krausmann, E., Cruz, A. M., \& Salzano, E. (2017). Glosary. In E. Krausmann, A. M. Cruz, \& E. Salzano (Eds.), Natech Risk Assessment and Management (pp. 241-243): Elsevier.

Krausmann, E., Fendler, R., Averous-Monnery, S., Cruz, A. M., \& Kato, N. (2017). Chapter 4 - Status of Natech Risk Management. In E. Krausmann, A. M. Cruz, \& E. Salzano (Eds.), Natech Risk Assessment and Management (pp. 53-68): Elsevier.

Krausmann, E., Köppke, K. E., Fendler, R., Cruz, A. M., \& Girgin, S. (2017). Chapter 8 - Qualitative and Semiquantitative Methods for Natech Risk Assessment. In E. Krausmann, A. M. Cruz, \& E. Salzano (Eds.), Natech Risk Assessment and Management (pp. 119-142): Elsevier.

Krausmann, E., \& Mushtaq, F. (2008). A qualitative Natech damage scale for the impact of floods on selected industrial facilities. Natural Hazards, 46(2), 179-197. doi:10.1007/s11069-007-9203-5

Kwag, S., \& Hahm, D. (2018). Development of an earthquake-induced landslide risk assessment approach for nuclear power plants. Nuclear Engineering and Technology. doi:https://doi.org/10.1016/j.net.2018.07.016

Landucci, G., Antonioni, G., Tugnoli, A., \& Cozzani, V. (2012). Release of hazardous substances in flood events: Damage model for atmospheric storage tanks. Reliability Engineering \& System Safety, 106, 200-216. doi:https://doi.org/10.1016/j.ress.2012.05.010

Landucci, G., Necci, A., Antonioni, G., Tugnoli, A., \& Cozzani, V. (2014). Release of hazardous substances in flood events: Damage model for horizontal cylindrical vessels. Reliability Engineering \& System Safety, 132, 125-145. doi:https://doi.org/10.1016/j.ress.2014.07.016

Landucci, G., Necci, A., Tugnoli, A., Antonioni, G., \& Cozzani, V. (2014) NaTech scenarios caused by flooding: Evaluation of accident frequency by the use of fragility models. In: Vol. 36. Chemical Engineering Transactions (pp. 427-432).

Landucci, G., Tugnoli, A., Antonioni, G., \& Cozzani, V. (2013) Damage models for storage and process equipment involved in flooding events. In: Vol. 31. Chemical Engineering Transactions (pp. 697-702).

Lanzano, G., Salzano, E., de Magistris, F. S., \& Fabbrocino, G. (2013). Seismic vulnerability of natural gas pipelines. Reliability Engineering \& System Safety, 117, 73-80. doi:10.1016/j.ress.2013.03.019

Lanzano, G., Salzano, E., Santucci de Magistris, F., \& Fabbrocino, G. (2014). Seismic vulnerability of gas and liquid buried pipelines. Journal of Loss Prevention in the Process Industries, 28, 72-78. doi:https://doi.org/10.1016/j.jlp.2013.03.010

Liu, K., Wang, M., Cao, Y., Zhu, W., \& Yang, G. (2018). Susceptibility of existing and planned Chinese railway system subjected to rainfall-induced multi-hazards. Transportation Research Part A: Policy and Practice, 117, 214-226. doi:https://doi.org/10.1016/j.tra.2018.08.030

Liu, T., Zhang, H., Li, X., \& Li, H. (2017). Effects of organization factors on flood-related Natechs in urban areas of China. Natural Hazards, 88(1), 355-365. doi:10.1007/s11069-017-2868-5

Lozoya, J. P., Sardá, R., \& Jiménez, J. A. (2011). A methodological framework for multi-hazard risk assessment in beaches. Environmental Science \& Policy, 14(6), 685-696. doi:https://doi.org/10.1016/j.envsci.2011.05.002

Mahendra, R. S., Prakash, C. M., Srinivasa Kumar, T., Shenoi, S. S. C., \& Shailesh, R. N. (2010). Coastal Multi-Hazard Vulnerability Mapping: A Case Study Along The Coast of Nellore District, East Coast of India. Rivista Italiana di Telerilevamento - Italian Journal of Remote Sensing, 42, 67-76. doi:10.5721/ItJRS20104235

Mara, S., Tanasescu, M., Ozunu, A., \& Vlad, S. N. (2007). Criteria for identifying the major risks associated with tailings ponds in Romania. Mine Water and the Environment, 26(4), 256-263. doi:10.1007/s10230-007-0018-0

Marzo, E., Busini, V., \& Rota, R. (2015). Definition of a short-cut methodology for assessing the vulnerability of a territory in natural-technological risk estimation. Reliability Engineering \& System Safety, 134, 92-97. doi:https://doi.org/10.1016/j.ress.2014.07.026

Marzocchi, W., Garcia-Aristizabal, A., Gasparini, P., Mastellone, M. L., \& Ruocco, A. D. (2012). Basic principles of multi-risk assessment: A case study in Italy. Natural Hazards, 62(2), 551-573. doi:10.1007/s11069-012-0092-X

Meng, Y., Lu, C., Yan, Y., Shi, L., \& Liu, J. (2015). Method to analyze the regional life loss risk by airborne chemicals released after devastating earthquakes: A simulation approach. Process Safety and Environmental Protection, 94, 366-379. doi:https://doi.org/10.1016/j.psep.2014.09.001

Mukherjee, S., Nateghi, R., \& Hastak, M. (2018). A multi-hazard approach to assess severe weather-induced major power outage risks in the U.S. Reliability Engineering \& System Safety, 175, 283-305. doi:https://doi.org/10.1016/j.ress.2018.03.015 
Naderpour, M., \& Khakzad, N. (2018). Texas LPG fire: Domino effects triggered by natural hazards. Process Safety and Environmental Protection, 116, 354-364. doi:https://doi.org/10.1016/j.psep.2018.03.008

Nadim, F., Liu, Z., Vangelsten, B., Garcia-Aristizabal, A., Woo, G., Aspinall, W., . . . Gelder, P. H. A. J. M. (2013). D5.2 Framework for multi-risk assessment. MATRIX project. Retrieved from

Nascimento, K. R. D. S., \& Alencar, M. H. (2016). Management of risks in natural disasters: A systematic review of the literature on NATECH events. Journal of Loss Prevention in the Process Industries, 44, 347-359. doi:https://doi.org/10.1016/j.jlp.2016.10.003

Necci, A., Antonioni, G., Cozzani, V., Borghetti, A., \& Nucci, C. A. (2013) Reduction of natech risk due to lightning by the use of protection systems. In: Vol. 31. Chemical Engineering Transactions (pp. 763768).

Necci, A., Antonioni, G., Cozzani, V., Borghetti, A., \& Nucci, C. A. (2014) Quantification of risk reduction due to the installation of different lightning protection solutions for large atmospheric storage tanks. In: Vol. 36. Chemical Engineering Transactions (pp. 481-486).

Necci, A., Antonioni, G., Cozzani, V., Krausmann, E., Borghetti, A., \& Alberto Nucci, C. (2013). A model for process equipment damage probability assessment due to lightning. Reliability Engineering \& System Safety, 115, 91-99. doi:https://doi.org/10.1016/j.ress.2013.02.018

Necci, A., Antonioni, G., Cozzani, V., Krausmann, E., Borghetti, A., \& Nucci, C. A. (2014). Assessment of lightning impact frequency for process equipment. Reliability Engineering \& System Safety, 130, 95105. doi:https://doi.org/10.1016/j.ress.2014.05.001

Necci, A., Antonioni, G., Krausmann, E., Argenti, F., Landucci, G., \& Cozzani, V. (2013) Accident scenarios caused by lightning impact on atmospheric storage tanks. In: Vol. 32. Chemical Engineering Transactions (pp. 139-144).

Necci, A., Argenti, F., Landucci, G., \& Cozzani, V. (2014). Accident scenarios triggered by lightning strike on atmospheric storage tanks. Reliability Engineering \& System Safety, 127, 30-46. doi:https://doi.org/10.1016/j.ress.2014.02.005

Necci, A., Cozzani, V., Spadoni, G., \& Khan, F. (2015). Assessment of domino effect: State of the art and research Needs. Reliability Engineering \& System Safety, 143, 3-18. doi:https://doi.org/10.1016/j.ress.2015.05.017

Newman, J. P., Maier, H. R., Riddell, G. A., Zecchin, A. C., Daniell, J. E., Schaefer, A. M., . . Newland, C. P. (2017). Review of literature on decision support systems for natural hazard risk reduction: Current status and future research directions. Environmental Modelling \& Software, 96, 378-409. doi:https://doi.org/10.1016/j.envsoft.2017.06.042

OECD. (2015). Addendum number 2 to the OECD guiding principles for chemical accident prevention preparedness and response to address natural hazards triggering technological accidents (NATECHs). In OECD (Ed.), (2th ed.). Paris, Francia.

Olivar, O. J. R., Mayorga, S. Z., Cruz, A. M., Pinelli, J. P., Salzano, E., Giraldo, F. M., \& Sánchez-Silva, M. (2018). Vulnerability and risk assessment analysis of natech events caused by natural phenomena. Paper presented at the Institution of Chemical Engineers Symposium Series.

Panico, A., Basco, A., Lanzano, G., Pirozzi, F., Santucci de Magistris, F., Fabbrocino, G., \& Salzano, E. (2017). Evaluating the structural priorities for the seismic vulnerability of civilian and industrial wastewater treatment plants. Safety Science, 97, 51-57. doi:https://doi.org/10.1016/j.ssci.2015.12.030

Paolacci, F., Giannini, R., \& De Angelis, M. (2013). Seismic response mitigation of chemical plant components by passive control techniques. Journal of Loss Prevention in the Process Industries, 26(5), 924-935. doi:https://doi.org/10.1016/j.jlp.2013.03.003

Pilone, E., \& Demichela, M. (2018). A semi-quantitative methodology to evaluate the main local territorial risks and their interactions. Land Use Policy, 77, 143-154. doi:https://doi.org/10.1016/j.landusepol.2018.05.027

Reniers, G., Khakzad, N., Cozzani, V., \& Khan, F. (2018). The impact of nature on chemical industrial facilities: Dealing with challenges for creating resilient chemical industrial parks. Journal of Loss Prevention in the Process Industries, 56, 378-385. doi:https://doi.org/10.1016/j.jlp.2018.09.010

Renni, E., Basco, A., Busini, V., Cozzani, V., Krausmann, E., Rota, R., \& Salzano, E. (2010) Awareness and mitigation of NaTech accidents: Toward a methodology for risk assessment. In: Vol. 19. Chemical Engineering Transactions (pp. 383-389).

Renni, E., Krausmann, E., \& Cozzani, V. (2010). Industrial accidents triggered by lightning. Journal of Hazardous Materials, 184(1), 42-48. doi:https://doi.org/10.1016/j.jhazmat.2010.07.118 
Renni, E., Paolone, M., Borghetti, A., Nucci, C. A., Krausmann, E., \& Cozzani, V. (2010). Assessment of the probability of structural damage due to lightning impact on process equipment in the chemical and process industry. Paper presented at the 10th International Conference on Probabilistic Safety Assessment and Management 2010, PSAM 2010.

Sahoo, B., \& Bhaskaran, P. K. (2018). Multi-hazard risk assessment of coastal vulnerability from tropical cyclones - A GIS based approach for the Odisha coast. Journal of Environmental Management, 206, 1166-1178. doi:https://doi.org/10.1016/j.jenvman.2017.10.075

Salzano, E., Basco, A., Busini, V., Cozzani, V., Marzo, E., Rota, R., \& Spadoni, G. (2013). Public awareness promoting new or emerging risks: Industrial accidents triggered by natural hazards (NaTech). Journal of Risk Research, 16(3-4), 469-485. doi:10.1080/13669877.2012.729529

Salzano, E., Garcia Agreda, A., Di Carluccio, A., \& Fabbrocino, G. (2009). Risk assessment and early warning systems for industrial facilities in seismic zones. Reliability Engineering \& System Safety, 94(10), 1577-1584. doi:https://doi.org/10.1016/j.ress.2009.02.023

Santella, N., Steinberg, L. J., \& Aguirra, G. A. (2011). Empirical Estimation of the Conditional Probability of Natech Events Within the United States. Risk Analysis, 31(6), 951-968. doi:10.1111/j.15396924.2010.01561.x

Soto, D., \& Renard, F. (2015). New prospects for the spatialisation of technological risks by combining hazard and the vulnerability of assets. Natural Hazards, 79(3), 1531-1548. doi:10.1007/s11069-015-1912-6

Steinberg, L. J., Sengul, H., \& Cruz, A. M. (2008). Natech risk and management: an assessment of the state of the art. Natural Hazards, 46(2), 143-152. doi:10.1007/s11069-007-9205-3

Stults, M. (2017). Integrating climate change into hazard mitigation planning: Opportunities and examples in practice. Climate Risk Management, 17, 21-34. doi:https://doi.org/10.1016/j.crm.2017.06.004

Tolo, S., Patelli, E., \& Beer, M. (2014). Bayesian Network Approach for Risk Assessment of a Spent Nuclear Fuel Pond. Paper presented at the Vulnerability, Uncertainty, and Risk: Quantification, Mitigation, and Management - Proceedings of the 2nd International Conference on Vulnerability and Risk Analysis and Management, ICVRAM 2014 and the 6th International Symposium on Uncertainty Modeling and Analysis, ISUMA 2014.

Tolo, S., Patelli, E., \& Beer, M. (2017). Risk Assessment of Spent Nuclear Fuel Facilities Considering Climate Change. Asce-Asme Journal of Risk and Uncertainty in Engineering Systems Part a-Civil Engineering, 3(2), 15. doi:10.1061/ajrua6.0000874

Urlainis, A., Shohet, I. M., \& Levy, R. (2015). Probabilistic Risk Assessment of Oil and Gas Infrastructures for Seismic Extreme Events. Procedia Engineering, 123, 590-598. doi:https://doi.org/10.1016/j.proeng.2015.10.112

van Westen, C. J., Montoya, L., Boerbom, L., \& badilla Coto, E. (2002). Multi-hazard risk assessment using GIS in urban areas: a case study for the city of Turrialba, Costa Rica. Paper presented at the Proceedings of the Regional Workshop on Best Practices in Disaster Mitigation: Lessons Learned from the Asian Urban Disaster Mitigation Program and Other Initiatives Bali, Indonesia.

Viavattene, C., Jiménez, J. A., Ferreira, O., Priest, S., Owen, D., \& McCall, R. (2018). Selecting coastal hotspots to storm impacts at the regional scale: a Coastal Risk Assessment Framework. Coastal Engineering, 134, 33-47. doi:https://doi.org/10.1016/j.coastaleng.2017.09.002

Villegas-González, P. A., Ramos-Cañón, A. M., González-Méndez, M., González-Salazar, Ramón E., \& De Plaza-Solórzano, J. S. (2017). Territorial vulnerability assessment frame in Colombia: Disaster risk management. International Journal of Disaster Risk Reduction, 21, 384-395. doi:https://doi.org/10.1016/j.ijdrr.2017.01.003

Wipulanusat, W., Nakrod, S., \& Prabnarong, P. (2009). Multi-hazard Risk Assessment Using GIS and RS Applications: A Case Study of Pak Phanang Basin. 6, 109-125. doi:10.2004/wjst.v6i1.76

Yang, Y., Chen, G., \& Chen, P. (2018). The probability prediction method of domino effect triggered by lightning in chemical tank farm. Process Safety and Environmental Protection, 116, 106-114. doi:https://doi.org/10.1016/j.psep.2018.01.019

Young, S., Balluz, L., \& Malilay, J. (2004). Natural and technologic hazardous material releases during and after natural disasters: a review. Science of The Total Environment, 322(1), 3-20. doi:https://doi.org/10.1016/S0048-9697(03)00446-7

Zimmaro, P., Stewart, J. P., Brandenberg, S. J., Kwak, D. Y., \& Jongejan, R. (2018). Multi-hazard system reliability of flood control levees. Soil Dynamics and Earthquake Engineering. doi:https://doi.org/10.1016/j.soildyn.2018.04.043 
Zuccaro, G., De Gregorio, D., \& Leone, M. F. (2018). Theoretical model for cascading effects analyses. International Journal of Disaster Risk Reduction, 30, 199-215. doi:https://doi.org/10.1016/j.ijdrr.2018.04.019

Zuccaro, G., \& Leone, M. F. (2018). Building Resilient Cities: A Simulation-Based Scenario Assessment Methodology for the Integration of DRR and CCA in a Multi-Scale Design Perspective. Procedia Engineering, 212, 871-878. doi:https://doi.org/10.1016/j.proeng.2018.01.112 